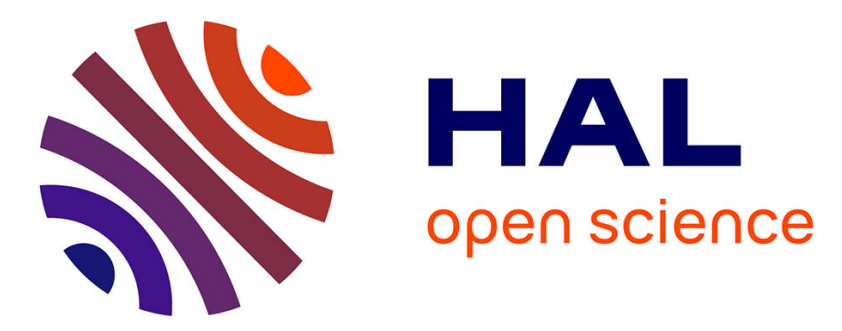

\title{
A global survey of the instantaneous linkages between cloud vertical structure and large-scale climate
} Ying Li, David W. J. Thompson, Graeme L. Stephens, Sandrine Bony

\section{To cite this version:}

Ying Li, David W. J. Thompson, Graeme L. Stephens, Sandrine Bony. A global survey of the instantaneous linkages between cloud vertical structure and large-scale climate. Journal of Geophysical Research: Atmospheres, 2014, 119 (7), pp.3770-3792. 10.1002/2013JD020669 . hal-01074224

\section{HAL Id: hal-01074224 \\ https://hal-polytechnique.archives-ouvertes.fr/hal-01074224}

Submitted on 23 Oct 2021

HAL is a multi-disciplinary open access archive for the deposit and dissemination of scientific research documents, whether they are published or not. The documents may come from teaching and research institutions in France or abroad, or from public or private research centers.
L'archive ouverte pluridisciplinaire HAL, est destinée au dépôt et à la diffusion de documents scientifiques de niveau recherche, publiés ou non, émanant des établissements d'enseignement et de recherche français ou étrangers, des laboratoires publics ou privés.

$$
\text { Copyright }
$$




\section{Journal of Geophysical Research: Atmospheres}

\section{RESEARCH ARTICLE}

10.1002/2013JD020669

Key Points:

- Quantify linkages between cloud vertical structure and meteorological parameters

- The linkages are explored and quantified at all levels and throughout the globe

- Provide a baseline for evaluating physical parameterizations of clouds in GCMs

Correspondence to:

Y. Li,

yingli@atmos.colostate.edu

Citation:

Li, Y., D. W. J. Thompson, G. L. Stephens, and S. Bony (2014), A global survey of the instantaneous linkages between cloud vertical structure and large-scale climate, J. Geophys. Res. Atmos., 119, 3770-3792, doi:10.1002/2013JD020669.

Received 1 AUG 2013

Accepted 13 FEB 2014

Accepted article online 18 FEB 2014

Published online 9 APR 2014

\section{A global survey of the instantaneous linkages between cloud vertical structure and large-scale climate}

\author{
Ying Li ${ }^{1}$, David W. J. Thompson ${ }^{1}$, Graeme L. Stephens ${ }^{2}$, and Sandrine Bony ${ }^{3}$ \\ ${ }^{1}$ Department of Atmospheric Science, Colorado State University, Fort Collins, Colorado, USA, ${ }^{2}$ Jet Propulsion Laboratory, \\ California Institute of Technology, Pasadena, California, USA, ${ }^{3}$ Laboratoire de Météorologie Dynamique, IPSL, CNRS, \\ Université Pierre et Marie Curie, Paris, France
}

\begin{abstract}
The instantaneous linkages between cloud vertical structure and various large-scale meteorological parameters are investigated using 5 years of data from the CloudSat/CALIPSO instruments. The linkages are systemically explored and quantified at all vertical levels and throughout the global ocean in both the long-term mean and on month-to-month timescales. A number of novel large-scale meteorological parameters are used in the analysis, including tropopause temperatures, upper tropospheric stability, and storm track activity. The results provide a baseline for evaluating physical parameterizations of clouds in GCMs and a reference for interpreting the signatures of large-scale atmospheric phenomena in cloud vertical structure. In the long-term mean, upper tropospheric cloud incidence throughout the globe increases with (1) decreasing tropopause temperature (at a rate of $\sim 2-4 \% \mathrm{~K}^{-1}$ ), (2) decreasing upper tropospheric stability $\left(\sim 5-10 \%\right.$ per $\left.\mathrm{K} \mathrm{km}^{-1}\right)$, and (3) increasing large-scale vertical motion ( 1-4\% per $\left.10 \mathrm{hPa} \mathrm{d}^{-1}\right)$. In contrast, lower tropospheric cloud incidence increases with (1) increasing lower tropospheric stability $\left(10 \%\right.$ per $\left.\mathrm{K} \mathrm{km}^{-1}\right)$ and descending motion ( $1 \%$ per $\left.10 \mathrm{hPa} \mathrm{d}^{-1}\right)$ in regions of subtropical regime but (2) decreasing lower tropospheric stability $\left(4 \%\right.$ per $\mathrm{K} \mathrm{km}^{-1}$ ) and ascending motion (2\% per $10 \mathrm{hPa}$ $\mathrm{d}^{-1}$ ) over the Arctic region. Variations in static stability and vertical motion account for $\sim 20-35 \%$ of the month-to-month variance in upper tropospheric cloudiness but less than $10 \%$ of the variance in lower tropospheric clouds. Upper tropospheric cloud incidence in the storm track regions is strongly linked to the variance of large-scale vertical motion and thus the amplitude of baroclinic waves.
\end{abstract}

\section{Introduction}

Clouds have a profound impact on the Earth's radiation budget [e.g., Ramanathan et al., 1989; Rossow and Lacis, 1990; Wielicki et al., 1995; Stephens, 2005; Bony et al., 2006]. They cool the Earth by reflecting incoming shortwave radiation back to space but warm the Earth by trapping outgoing longwave radiation. Changes in cloud amount modify the radiative and latent heating of the atmosphere and thus also influence the large-scale atmospheric circulation [Slingo and Slingo, 1988; Randall et al., 1989; Stephens, 2005]. But despite their importance for climate, the representation of clouds in current climate models remains challenging [e.g., Bony et al., 2004; Zhang et al., 2005; Nam et al., 2012; Jiang et al., 2012; Li et al., 2012a; Klein et al., 2013; Su et al., 2013], and cloud radiative feedback remains a major source of uncertainty in predicting future climate change [e.g., Stephens, 2005; Bony et al., 2006; Soden and Held, 2006; Randall et al., 2007; Dufresne and Bony, 2008].

The interpretation of (and thus our ability to improve) the representation of clouds in models is limited by our poor knowledge of the near-global vertical structure of clouds in observations. Observational uncertainty in cloud vertical structure underlies many compensating errors suffered in climate models, including compensating errors between clouds at different heights to simulate the total cloud amount and between cloud fraction and cloud optical properties to simulate the cloud radiative fluxes [Webb et al., 2001; Zhang et al., 2005; Nam et al., 2012; Klein et al., 2013]. In addition, clouds at different altitudes and with varying optical depths affect the Earth's radiation budget in different ways, and detailed information of the global three-dimensional structure of clouds is key for determining the vertical distribution of radiative heating rates [Wielicki and Parker, 1992; Chen et al., 2000; Weare, 2000].

Existing global cloud data sets, such as the International Satellite Cloud Climatology Project [Rossow and Schiffer, 1991, 1999], provide valuable information on the horizontal distribution of clouds but relatively 
little information on cloud vertical structure due to the limitations of the passive-sensing instruments on which they are based. Passive instruments also have difficulties detecting thin upper level clouds and clouds forming over snow or ice. The active remote sensors on board the CloudSat and Cloud-Aerosol Lidar and Infrared Pathfinder Satellite Observation (CALIPSO) satellites provide the first global-scale data set of cloud vertical structure [Stephens et al., 2002].

Our ability to understand and simulate clouds and cloud feedback hinges on observations of not only the vertical structure of clouds but also the two-way linkages between cloud frequency and the meteorology as a function of vertical level. Considerable effort has been placed on understanding the relationships between the meteorology and low-level clouds. For example, periods and regions of relatively low sea surface temperature (SST) and high lower tropospheric stability are marked by increased abundances of marine stratocumulus, and vice versa. The linkages between marine stratocumulus, SST, and lower tropospheric stability have been investigated on seasonal timescales [Klein and Hartmann, 1993; Wood and Bretherton, 2006; Richter and Mechoso, 2004, 2006; Jensen et al., 2008; Lin et al., 2009; Kubar et al., 2011], synoptic timescales [Klein, 1997; Norris and Klein, 2000; George and Wood, 2010], and interannual timescales [Hanson, 1991; Oreopoulos and Davies, 1993; Norris and Leovy, 1994; Klein et al., 1995; Clement, 2009; Eastman et al., 2011; Eitzen et al., 2011; Kubar et al., 2012]. Numerous studies have examined the key role of various dynamic and thermodynamic processes on the formation of marine stratocumulus [Hanson, 1991; Klein, 1997; Bony et al., 1997; Norris and Klein, 2000; Wood and Bretherton, 2006; Wood, 2012]. And several other studies have noted that the out-of-phase linkages between SSTs and marine stratiform cumulus have implications for climate feedback [Hanson, 1991; Klein and Hartmann, 1993; Bony and Dufresne, 2005; Zhu et al., 2007].

Considerable effort has also been placed on understanding the relationships between the meteorology and clouds at upper levels, particularly deep convective and cirrus clouds in the tropics. The linkages between the meteorology and the spatially varying distribution of deep convection have been examined extensively on seasonal timescales [Zhang, 1993a], intraseasonal timescales in association with Madden-Julian oscillation [Eguchi and Shiotani, 2004; Masunaga et al., 2008; Chen and Genio, 2009; Tromeur and Rossow, 2010; Jiang et al., 2011; Riley et al., 2011; Yuan and Houze, 2013], and interannual timescales in association with El Niño-Southern Oscillation [Fu et al., 1990; Ramanathan and Collins, 1991; Zhang et al., 1996; Cess et al., 2001a, 2001b; Allan et al., 2002; Park and Leovy, 2004; Guilyardi et al., 2009; Su and Jiang, 2013; Lacagnina and Selten, 2013]. The large-scale distribution of deep convective clouds is closely tied to the distribution of SSTs [Ramanathan and Collins, 1991; Waliser et al., 1993; Zhang, 1993b; Bony et al., 1997; Lau et al., 1997; Behrangi et al., 2012] and vertical motion in the free troposphere [Bony et al., 1997, 2004; Wyant et al., 2006; Zhang et al., 2007]. It is also linked to the structure of tropopause temperature [Zhang, 1993a; Gettelman et al., 2002], near-surface moisture convergence [Lindzen and Nigam, 1987], upper tropospheric humidity [Soden and Fu, 1995; Sassi et al., 2001; Su et al., 2006a], and radiatively driven divergence [Kubar et al., 2007; Zelinka and Hartmann, 2011; Li et al., 2012b]

The linkages between the meteorology and the spatially varying distribution of optically thin cirrus in the tropical tropopause transition layer (TTL) have also received increasing attention in recent years, in large part due to the advent of the CALIPSO data. The temporal and spatial structure of cirrus in the TTL has been linked to tropical stratospheric waves in field experiment data [Boehm and Verlinde, 2000] and large-scale equatorial waves on seasonal, intraseasonal, and interannual timescales in 3 years of CALIPSO measurements [Virts and Wallace, 2010]. CloudSat and CALIPSO data have also been used to demonstrate a robust link between the stratospheric Brewer-Dobson circulation and cloud amount in both the TTL and Arctic troposphere [Li and Thompson, 2013].

The objective of this study is to exploit vertically resolved cloud incidence from the CloudSat/CALIPSO instruments to document and interpret the observed linkages between the meteorology and cloud incidence as a function of vertical level throughout the global ocean. We will focus primarily on instantaneous relationships between clouds and the meteorology since both fields can vary on submonthly timescales. Instantaneous relationships are also likely to provide more insight about the underlying physical processes than monthly-mean relationships. Previous studies have used the CloudSat data to examine the linkages between the meteorology and various cloud properties, but most have focused on relationships based on monthly or long-term mean (rather than instantaneous) versions of the data [e.g., Zhang et al., 2007; Su et al., 2011, 2013]. Su et al. [2008] examined the instantaneous linkages between the large-scale meteorology and clouds using the CloudSat data but focused primarily on the tropical oceans. Here we will systematically investigate the instantaneous linkages between cloud incidence and the meteorology over all regions of the global ocean. 
We will provide quantitative estimates of the linkages between cloud incidence and a range of controlling factors not widely considered in previous work, including tropopause temperatures, upper tropospheric stability, and storm track activity. Our use of tropopause temperature is novel and is motivated by recent evidence that variability in the large-scale stratospheric Brewer-Dobson circulation influences cloud incidence in both the tropical transition layer and Arctic troposphere via its signature in upwelling and downwelling at the tropopause level [ $L i$ and Thompson, 2013]. Tropopause temperature and upper tropospheric stability provide overlapping but complementary information about the conditions that give rise to variations in cloud incidence in the uppermost troposphere. In a sense, much as sea surface temperature can be viewed as setting the lower boundary condition for tropospheric cloud incidence, tropopause temperature can be viewed as setting the upper boundary condition.

Section 2 describes the satellite and reanalyses data sets used in the study. In section 3, we examine the long-term mean of the instantaneous (i.e., profile by profile) relationships between cloud incidence and large-scale meteorological parameters. The results are focused on clouds over the ocean and include analyses of the tropics, middle latitudes, and polar regions. In section 4, we use the insights gained from section 3 to interpret the linkages between cloud incidence and large-scale meteorological parameters on month-to-month timescales. Section 5 provides a summary and discussion of the results.

\section{Data and Methods}

The primary data used in the study are estimates of cloud fraction from the CloudSat and CALIPSO satellites. Launched in April 2006, CloudSat and CALIPSO are components of the NASA Afternoon Train (A-Train) constellation of satellites [Stephens et al., 2002]. The Cloud Profiling Radar (CPR) aboard CloudSat is a 94 GHz nadir-pointing radar that is able to measure optically thick hydrometeor layers. The lidar system carried by CALIPSO is capable of detecting optically thin cloud layers that could be missed by the CPR, such as those formed in the vicinity of the tropical tropopause [Winker et al., 2007]. However, the lidar becomes attenuated quickly in the presence of optically thick clouds and thus cannot detect some of the clouds identified by the radar [Mace et al., 2009]. Conversely, the CloudSat CPR is unable to detect most clouds below $1 \mathrm{~km}$ (due to contamination from the surface) [Marchand et al., 2008] and optically thick clouds with relatively small water droplets in the boundary layer (due to the limitation of the long wavelength of CPR) [Im et al., 2005], whereas the lidar is able to sense many clouds in the lowermost and uppermost parts of the atmosphere. Hence, the CPR and the CALIPSO lidars are complementary to each other and allow observations of cloud incidence from below $1 \mathrm{~km}$ to the stratosphere.

Cloud fraction data are obtained from the Level 2B Geometrical Profiling-LIDAR product (2B-GEOPROFLIDAR; version P2R04), which combines information from the CloudSat radar (i.e., the CPR) and the CALIPSO lidar [Mace et al., 2009]. As reported in Hagihara et al. [2010], CALIPSO version 2 data significantly overestimate the incidence of low-level clouds. The version P2R04 of the 2B-GEOPROF-LIDAR product used here incorporates CALIPSO version 3 data (http://www.cloudsat.cira.colostate.edu/dpcNewsltem.php? newsid=53) and is considered greatly improved in this regard [Vaughan et al., 2010]. The analyses here are based on roughly 5 years of the combined CloudSat and CALIPSO measurements from June 2006 through April 2011.

Cloud fraction data from the combined 2B-GEOPROF-LIDAR product are presented in terms of "cloud incidence." The CloudSat footprint is $1400 \mathrm{~m}$ cross track and $2500 \mathrm{~m}$ along track, and the vertical sampling is at roughly $240 \mathrm{~m}$. Cloud incidence is estimated by first assigning a " 1 " or " 0 " to all sample volumes depending on the sample cloud fraction: If the cloud fraction within the volume is greater than one half, then the volume is assigned a 1 ; if the cloud fraction within the volume is less than one half, then the volume is assigned a 0 . The resulting values of cloud incidence are then averaged over larger number of samples, depending on the analysis design. For example, the mean cloud incidence between 14 and $15 \mathrm{~km}$ in regions where SST is between 302 and $303 \mathrm{~K}$ is found by averaging cloud incidence over all volumes that lie within that sample space. A resulting mean cloud incidence of, say, $25 \%$ indicates that at least half of the volume is cloudy, $25 \%$ of the time. See Verlinden et al. [2011] for a more detailed description of the calculation of cloud incidence and the reason for using cloud incidence rather than ice/liquid water content.

We use two products to assess the linkages between the meteorology and cloud incidence. The primary data source is the CloudSat/European Centre for Medium-Range Weather Forecasts auxiliary product 
(ECMWF-AUX). The ECMWF-AUX product provides ECMWF state variable data interpolated onto the same spatial and temporal resolution as the CloudSat track. The ECMWF-AUX product is used to derive relationships between cloud incidence and potential temperature $(\theta)$, static stability $\left(\frac{\partial \theta}{\partial z}\right)$, tropopause temperature, and tropopause height (Tropopause height is identified using the World Meteorological Organization lapse rate definition.). It should be emphasized that the use of the high-frequency meteorological fields derived from ECMWF-AUX product (as opposed to the use of daily or monthly mean fields) is the key, as it allows us assess with high accuracy the instantaneous linkages between cloud incidence and the methodology.

In select cases, we also use monthly mean output from the European Centre for Medium Range Weather Forecasts (ECMWF) Interim Reanalysis (ERA-Interim) [Simmons et al., 2007; Dee et al., 2011]. The reanalysis is available on a $1.5^{\circ} \times 1.5^{\circ}$ horizontal mesh, at 37 pressure levels and every $6 \mathrm{~h}$, from 1979 to present. In cases where we use the ERA-Interim reanalysis, cloud incidence is resampled to $1.5^{\circ} \times 1.5^{\circ}$ grid boxes and averaged to form monthly means. The ERA-Interim reanalysis is used to derive relationships between cloud incidence and vertical velocity and the amplitude of the midlatitude storm track. Vertical velocity is used at $500 \mathrm{hPa}$ and is expressed as $-1 \times \omega_{500}$ such that positive value denote rising motion, and vice versa.

The amplitude of the midlatitude storm track is defined as the root-mean-square (RMS) of the daily $500 \mathrm{hPa}$ vertical pressure velocity $\left[\left(\overline{\omega^{\prime 2}}\right)^{1 / 2}\right]$, where the prime represents the daily deviation from the monthly mean, and the overbar denotes the monthly mean. Similar indices for the storm track activity have been used in Weaver and Ramanathan [1997], Norris [2000], and Norris and Weaver [2001]. Lower tropospheric stability is estimated as the difference in potential temperature between $3 \mathrm{~km}$ above the ocean surface $(\sim 700 \mathrm{hPa})$ and the surface [e.g., Klein and Hartmann, 1993] and is expressed at $\mathrm{K} \mathrm{km}^{-1}$. Upper tropospheric stability is defined in an analogous and generalized way as the difference in potential temperature between tropopause and $3 \mathrm{~km}$ below the tropopause. Note that our definition of upper tropospheric stability accounts for spatial and temporal variability in the height of the tropopause.

Results are shown for full and anomaly versions of the data. In the latter case, anomalies are formed by subtracting the long-term mean annual cycle from the data.

\section{Observed Linkages Between the Vertical Structures of Cloud Incidence and the Meteorology: Long-Term Mean}

In this section, we examine the vertical structure of cloud incidence as a function of a range of meteorological parameters throughout the globe. The results in this section are based on the long-term averages of the instantaneously observed relationships between the meteorology and clouds derived from the high-frequency individual profile measurements (i.e., the cloud data are binned as a function of the meteorology based on individual instantaneous profile measurements, and then the relationships are averaged over all $\sim 5$ years of data).

Figure 1 shows long-term mean maps of the primary meteorological parameters used in this section. From top to bottom, the figure shows long-term mean values of tropopause temperature (Figure 1a), upper tropospheric stability (Figure 1b), vertical velocity at $500 \mathrm{hPa}\left(\omega_{500} ; \omega\right.$ has been multiplied by -1 so that positive values correspond to upward motion) (Figure 1c), lower tropospheric stability (Figure 1d), and SST over the global ocean based on ERA-Interim reanalysis (Figure 1e). The results in Figure 1 will be referenced throughout the study, but several key covarying features among different parameters warrant brief mention before we examine the linkages between these fields and cloud structure.

In part by construction, much of the structure in tropopause temperatures is mirrored in upper tropospheric stability, i.e., regions of cold tropopause temperatures in the tropics (Figure 1a) are generally associated with weak upper tropospheric stability (Figure 1b). Likewise, much of the structure in the SST field is reflected in lower tropospheric stability, i.e., regions of relatively high SST are generally collocated with weak lower tropospheric stability (Figure 1d), and vice versa. Features in both upper and lower tropospheric stability are reflected in the midtropospheric vertical motion: regions of ascent are frequently collocated with relatively low static stability in both the upper and lower tropospheres, and vice versa. Regions of warm SSTs and ascending motion at $500 \mathrm{hPa}$ in the deep tropics and middle/high latitudes are generally collocated with low static stability in the upper and lower tropospheres. Note that the high degree of correspondence 
a) Annual mean tropopause temp

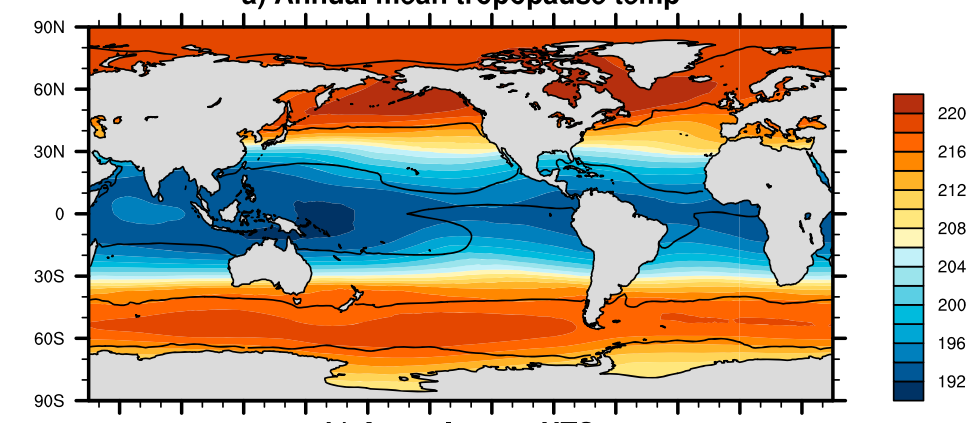

b) Annual mean UTS

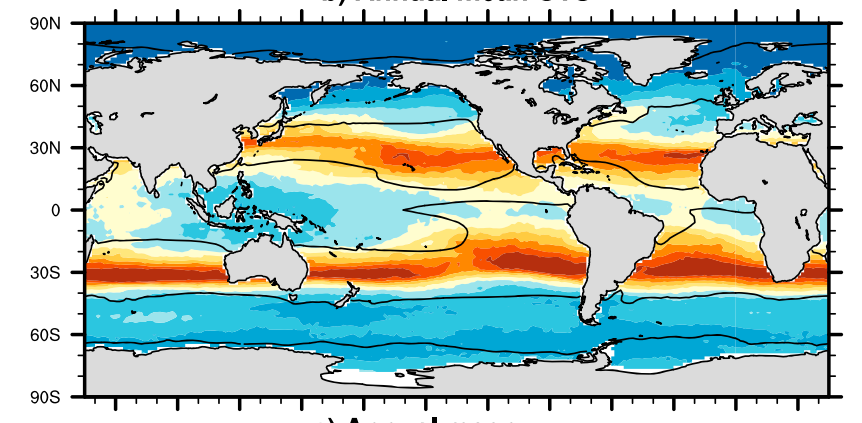

c) Annual mean $-\omega_{500}$
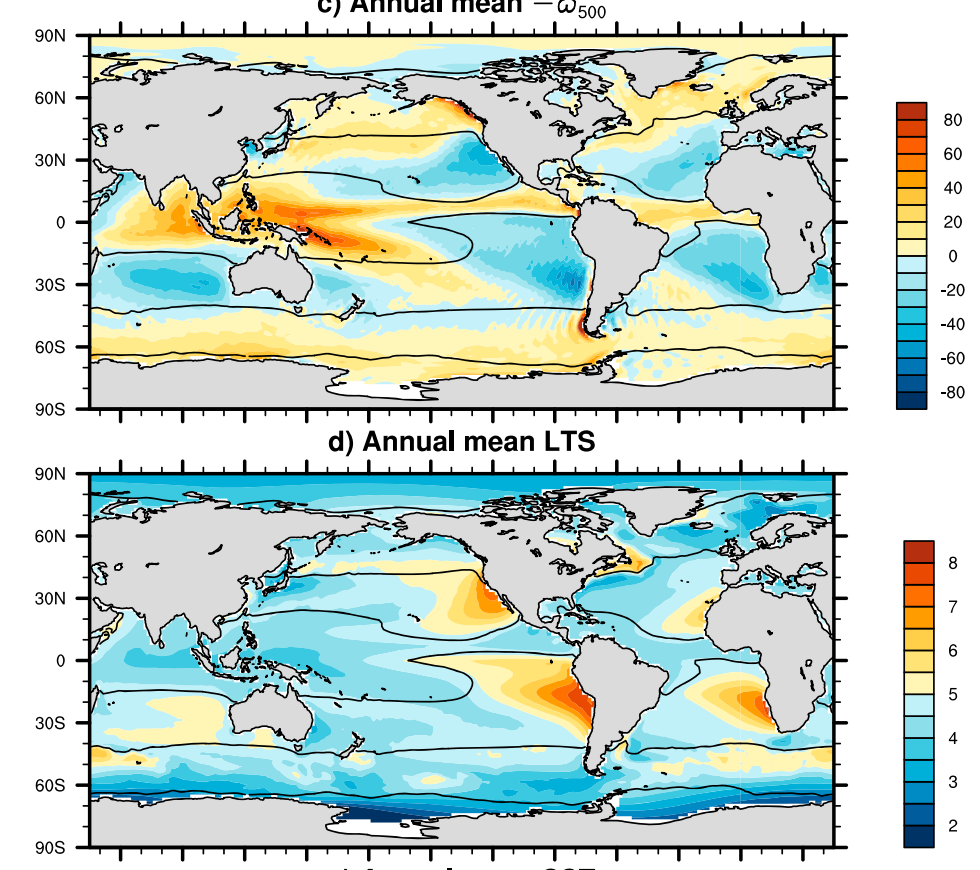

e) Annual mean SST

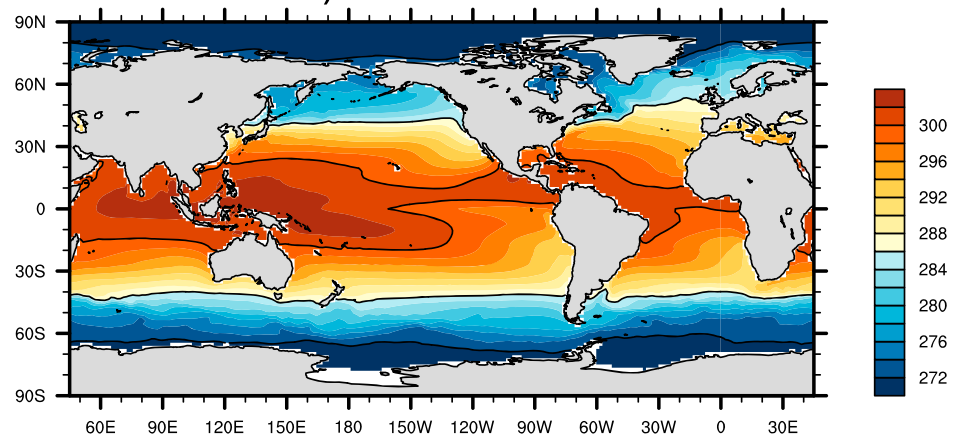

Figure 1 


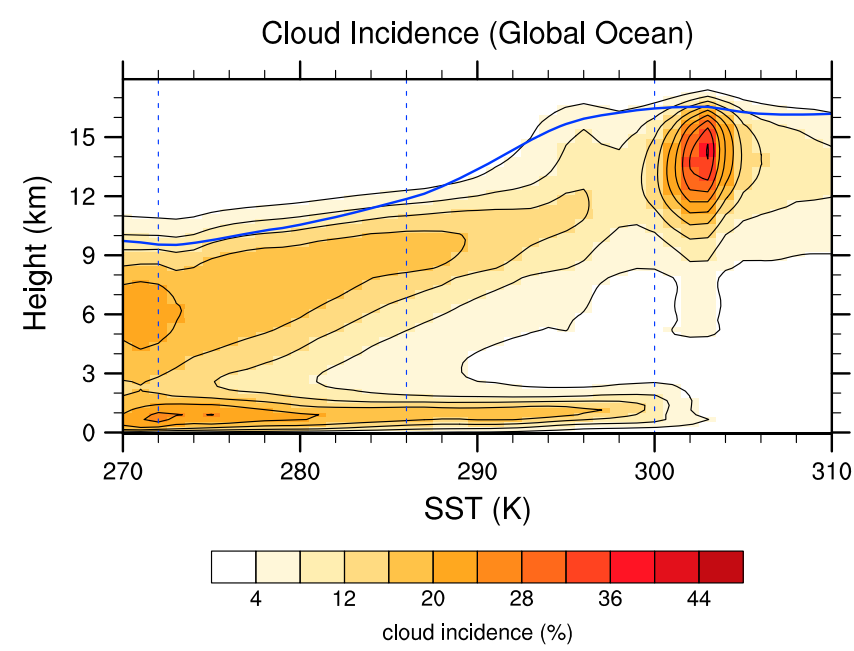

Figure 2. Vertical distribution of cloud incidence as a function of SST over the global ocean. SST bin with $1 \mathrm{~K}$ interval is used. The solid blue line corresponds to the height of tropopause as a function of SST over the global ocean. The dashed blue lines are the SST boundaries used to define the three distinct SST regimes for constructing plots in Figures 3-5.

height and SST, where the SST is binned in increments of $1 \mathrm{~K}$. Regions where skin temperature is below 270 $\mathrm{K}$ are considered covered by sea ice and are excluded from the analyses.

The resulting global distribution of cloud incidence as a function of height and SST is shown in Figure 2. The results are strongly influenced by the meridional structure of cloud incidence since SST decreases monotonically with latitude. However, the SST field also exhibits large zonal asymmetries (Figure 1e). Thus, the results are not identical to, say, cloud incidence shown as a function of latitude. A similar result based on CloudSat data was presented in Su et al. [2008, 2011] but only for the tropical ocean and 1 year of data.

The linkages between SST and cloud incidence can be viewed in the context of three distinct height regimes. At lower levels (below $\sim 3 \mathrm{~km}$ ), clouds decrease with increasing SSTs, consistent with the relationship between low clouds and lower tropospheric stability [e.g., Klein and Hartmann, 1993; Wood and Bretherton, 2006]. The rate of decrease is most rapid between 295 and $300 \mathrm{~K}$, which approximately corresponds to the subtropical/tropical transition region (Figure 1e). Cloud incidence remains relatively constant with increasing SST for SSTs lower than $295 \mathrm{~K}$, except for the shallow maximum in cloud incidence between $\sim 272$ and $278 \mathrm{~K}$.

At midtropospheric levels (between $\sim 3$ and $10 \mathrm{~km}$ ), cloud incidence decreases along a diagonal toward increasing SSTs and increasing height. The sloping upper bound on cloud incidence reflects the meridional structure of the tropopause (see solid blue line in Figure 2): the left side of the plot corresponds to high latitudes; the right side corresponds to the tropics. The minimum in cloud incidence around 295-300 K between 3 and $9 \mathrm{~km}$ marks the transition between tropics and extratropics and lies within the descending branch of the subtropical Hadley Cell (Figure 1c). The maximum in cloud incidence between 6 and $9 \mathrm{~km}$ for SSTs below $285 \mathrm{~K}$ reflects the midlatitude storm track regions (Figure 1e).

At upper tropospheric levels (above $\sim 10 \mathrm{~km}$ ), cloud incidence increases rapidly with SST up to $303 \mathrm{~K}$ but decreases with SST beyond that value. The increases in upper tropospheric cloud incidence for SSTs between 300 and $303 \mathrm{~K}$ are consistent with the relationships between SST and tropical deep convection

Figure 1. Geographic distribution of (a) tropopause temperature, (b) upper tropospheric stability (units: $\mathrm{K} \mathrm{km}^{-1}$ ), (c) vertical motion at $500 \mathrm{hPa}\left(-\omega_{500}\right.$; with positive values indicating upward motion), (d) lower tropospheric stability (units: $\mathrm{K} \mathrm{km}^{-1}$ ), and (e) SST during June 2006 through April 2010 based on ERA-Interim reanalysis. Lower tropospheric stability is estimated as the difference in potential temperature between $3 \mathrm{~km}$ and the surface, and upper tropospheric stability is estimated as the difference in potential temperature between tropopause and $3 \mathrm{~km}$ below the tropopause. See text for details. The black contour lines correspond to SST isotherm of 300, 286, and $272 \mathrm{~K}$. These are the boundaries for the three distinct SST regimes (see text in section 3.1 for details). 


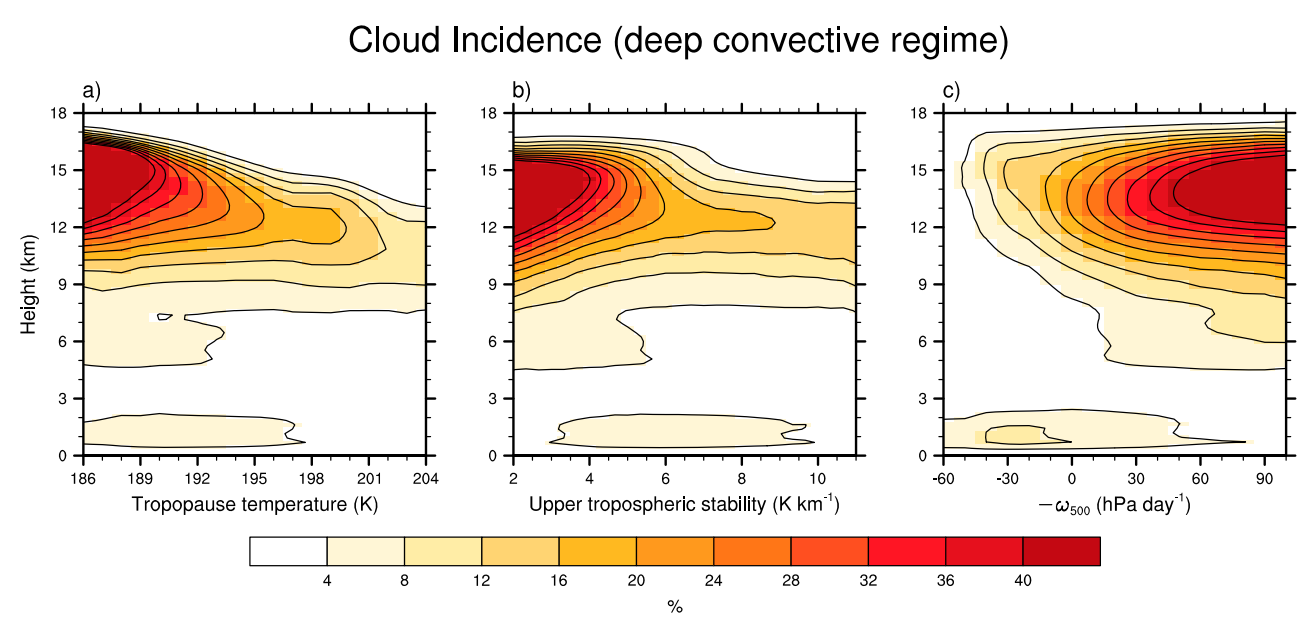

Figure 3. Vertical distribution of cloud incidence as a function of (a) tropopause temperature, (b) upper tropospheric stability, and (c) $-\omega_{500}$ in the deep convective regime.

[e.g., Lindzen and Nigam, 1987; Ramanathan and Collins, 1991; Waliser et al., 1993; Lau et al., 1997; Bony et al., 1997; Su et al., 2006a, 2006b; Behrangi et al., 2012]. The decreases in cloud incidence for SSTs warmer than $\sim 303 \mathrm{~K}$ are consistent with the decreased frequency of occurrence of large-scale rising motions over the highest SSTs [e.g., Waliser et al., 1993; Bony et al., 1997; Su et al., 2006b].

The linkages between SST and cloud incidence can also be viewed in the context of three distinct SST regimes. These are delineated as vertical dashed lines in Figure 2 and are the following:

1. SSTs greater than $300 \mathrm{~K}$. This regime includes most of clouds in the plot that lie above $\sim 12 \mathrm{~km}$ (Figure 2). The regime primarily includes the tropical convergence zone (Figure 1e) and will be denoted hereafter as the "deep convective regime."

2. SSTs between 286 and $300 \mathrm{~K}$. This regime in the SST/cloud incidence sample space is marked by widespread low-level clouds but a minimum in clouds (and thus relatively clear skies) at upper levels (Figure 2). The regime includes regions with strong subsidence and high lower tropospheric stability over the eastern side of the subtropical ocean basins and along the eastern Pacific equatorial cold tongue (Figures $1 \mathrm{c}$ and $1 \mathrm{~d}$ ). It will be denoted hereafter as the "subtropical regime."

3. SSTs between 272 and $286 \mathrm{~K}$. This regime is marked by widespread clouds at lower and upper levels

(Figure 2). It includes primarily the extratropics and midlatitude storm track region (Figure 1e) and will be denoted hereafter as the "middle-/high-latitude regime."

In the rest of this section, we will examine the linkages between cloud incidence and large-scale meteorological parameters in each of the three cloud/SST regimes outlined above. We will also examine separately results for (a) the midlatitude storm track regions over the North/South Pacific Ocean and North/South Atlantic Ocean and (b) the Arctic region poleward of $70^{\circ} \mathrm{N}$ (including sea ice regions). The data used in this section are not filtered to remove the seasonal cycle, and thus, the results include relationships due to the long-term mean and the annual march. Relationships due to month-to-month variability are examined in section 4. All meteorological fields are derived from the ECMWF-AUX product except for vertical motion, which is derived from ERA-Interim. Results based on the ECMWF-AUX product are derived from $\sim 1 \times 10^{8}$ profile measurements; results based on ERA-Interim are based on $\sim 2 \times 10^{5}$ monthly mean profiles.

\subsection{Deep Convective Regime}

The distribution of vertical motion and thus clouds in deep convective regions is determined by a variety of interrelated conditions, including temperatures at both the surface and the tropopause. As noted in Figure 2, the incidence of upper tropospheric clouds increases by $10 \% \mathrm{~K}^{-1}$ for SSTs between $\sim 300$ and $303 \mathrm{~K}$ and then decreases by $\sim 10 \% \mathrm{~K}^{-1}$ for SSTs between $\sim 303$ and $306 \mathrm{~K}$. Note that the rates quoted in the text are based on the height level where the regression coefficient between the cloud incidence and the corresponding meteorological parameter is largest. Figure 3 quantifies the linkages between the cloud incidence in the deep convective regime (SSTs greater than $300 \mathrm{~K}$ ) and three additional meteorological parameters: 


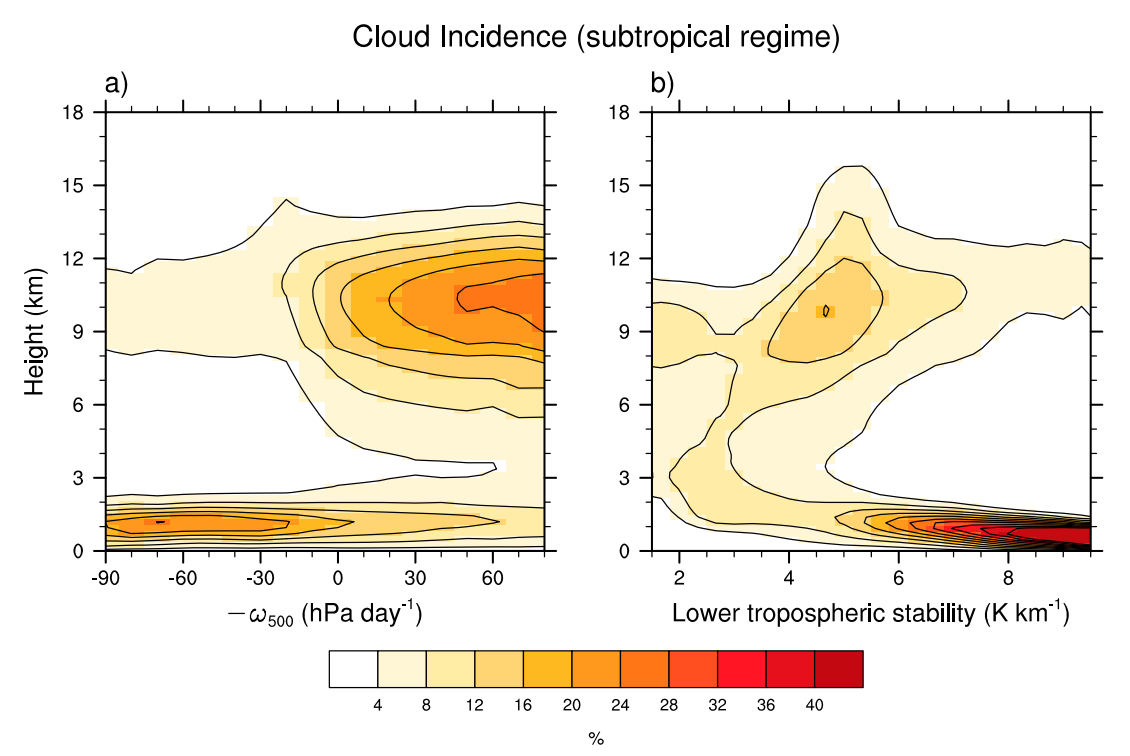

Figure 4. Vertical distribution of cloud incidence as a function of (a) $-\omega_{500}$ and (b) lower tropospheric stability in the subtropical regime.

(a) tropopause temperature, (b) upper tropospheric stability, and (c) vertical motion at $500 \mathrm{hPa}$ (shown as $-1 \times\left(\omega_{500}\right)$. The results are not sensitive to the specific level chosen for the analyses.

Upper tropospheric cloud incidence is strongly linked to thermodynamic and dynamic conditions in the upper troposphere. Cloud incidence increases by $4 \% \mathrm{~K}^{-1}$ as tropopause temperatures decrease from 198 to $189 \mathrm{~K} \mathrm{(Figure} \mathrm{3a).} \mathrm{The} \mathrm{linkages} \mathrm{between} \mathrm{upper} \mathrm{tropospheric} \mathrm{cloud} \mathrm{incidence} \mathrm{and} \mathrm{tropopause} \mathrm{temper-}$ atures (Figure 3a) are in part due to the coherence between tropopause temperatures and SSTs: regions of relatively high SSTs force large-scale equatorial waves, and such waves influence TTL temperatures and cirrus through adiabatic motions [e.g., Boehm and Lee, 2003; Norton, 2006; Dima and Wallace, 2007; Virts and Wallace, 2010; Grise and Thompson, 2012]. In the companion paper [Li and Thompson, 2013], we demonstrated that cloud incidence between 15 and $18 \mathrm{~km}$ is a much stronger function of tropopause temperature than SST, whereas cloud incidence between 10 and $15 \mathrm{~km}$ is an independent function of both SST and tropopause temperature.

The relationships between upper tropospheric cloud incidence and tropopause temperature are consistent with those derived for cloud incidence and upper tropospheric stability (Figure 3b). Cold tropopause temperatures are associated with low upper tropospheric stability (and presumably relatively strong upward motion). Thus, upper tropospheric cloud incidence increases by $10 \%$ per $\mathrm{K} \mathrm{km}^{-1}$ as upper tropospheric stability decreases from $\sim 6$ to $4 \mathrm{~K} \mathrm{~km}^{-1}$, and vice versa. Similarly, cloud incidence at upper levels increases by $4 \%$ for every $10 \mathrm{hPa} \mathrm{d}^{-1}$ increase in vertical motion at $500 \mathrm{hPa}$ (Figure 3c).

\subsection{Subtropical Regime}

The meteorological factors that govern the incidence of low-level subtropical marine clouds have also received considerable attention in the literature (e.g., see section 1). As noted in Figure 2, the incidence of low-level marine clouds decreases by $\sim 3 \% \mathrm{~K}^{-1}$ for SSTs between 290 and $300 \mathrm{~K}$. Figure 4 quantifies the linkages between cloud incidence in the subtropical regime (SSTs between 286 and $300 \mathrm{~K}$ ) and two additional meteorological parameters: (a) vertical velocity at $500 \mathrm{hPa}$ and (b) lower tropospheric stability. Boundary layer cloud incidence increases with increasing subsidence and lower tropospheric stability at rates of $1 \%$ per $10 \mathrm{hPa} \mathrm{d}^{-1}$ and $10 \%$ per $\mathrm{K} \mathrm{km}^{-1}$, respectively. Note that the near-surface cloud layer becomes increasingly shallow as lower tropospheric stability increases (Figure $4 b$ ).

The instantaneous linkages between low-level clouds, SST, midtropospheric vertical motion, and lower tropospheric stability are consistent with those documented extensively in the studies noted earlier using monthly mean data. Cold SSTs (Figure 2) and descending motion in the midtroposphere (Figure 4a) both lead to increased lower static stability and thus increased cloud incidence in the marine boundary layer 
(Figure 4b). Descending motion and high static stability limit the vertical extension of the clouds above the boundary layer.

It should be noted that the linkages between cloud incidence and lower tropospheric stability is rather weak in regions where lower tropospheric stability is relatively small (Figure $4 b$ ). The weak lower tropospheric stability in the subtropical regime approximately corresponds to the SST fronts near the eastern coast of the continents (Figure 1d), where surface wind convergence/divergence may play a more important role in cloud formation. Regions with surface convergence are mostly associated with upward motion and thus increased midlevel and high-level cloud incidence (Figure 4a) but not necessarily with weak lower tropospheric stability. The linkages between cloud incidence and lower tropospheric stability in regions of weak static stability may also reflect the influence of shallow convective mixing on planetary boundary layer relative humidity. That is, in regions of weak lower tropospheric stability, shallow convective mixing can act to import dry air from the lower free troposphere into the planetary boundary layer and thus reduce the relative humidity there [Stevens, 2007].

The results in Figure 4 reveal several additional interesting features also worth noting. Low-level clouds are overlapped by high clouds even in regions with strong subsidence and lower tropospheric stability [see Christensen et al., 2013; Yuan and Oreopoulos, 2013]. As noted in Yuan and Oreopoulos [2013], the overlap rate is $5 \%$ in such subsidence regions. Nam et al. [2012] pointed out that the overestimation of the low clouds by middle and high clouds in GCMs introduced one source of the compensating errors in the simulations of radiative fluxes at the top of the atmosphere. Low-level clouds extend above the boundary layer and appear to merge with clouds in the free troposphere when the lower tropospheric stability falls below $5 \mathrm{~K} \mathrm{~km}^{-1}$ (Figure 4b). The merging of boundary layer and midtropospheric clouds in regions of low static stability is consistent with the signatures of cumulus congestus clouds. It might also indicate trade cumulus clouds, as cloudy air in the region of subtropical stratus decks is advected equatorward and westward by the trade winds toward warmer waters [e.g., Wyant et al., 1997]. The peak in cloud incidence between 9 and $12 \mathrm{~km}$ in regions of relatively weak lower tropospheric stability and ascent might reflect the intrusion of midlatitude synoptic system into the subtropics.

\subsection{Middle-/High-Latitude Regime}

Cloud incidence and cloud radiative forcing in the northern midlatitudes are linked to the large-scale vertical motion at 500 hPa [Weaver and Ramanathan, 1997; Norris and Weaver, 2001; Tselioudis and Jakob, 2002], surface pressure [Tselioudis et al., 2000], temperature advection [Lau and Crane, 1995], static stability [Klein and Hartmann, 1993; Weaver and Ramanathan, 1997], and SSTs [Norris and Leovy, 1994]. As noted in association with Figure 2, cloud incidence in the middle-/high-latitude regime (SSTs between $\sim 272$ and $286 \mathrm{~K}$ ) exhibits a distinct vertical structure, with maxima near the surface and the tropopause, and a minimum in the middle troposphere. Figure 5 quantifies the linkages between cloud incidence in the middle-/high-latitude regime and four additional meteorological parameters (a) tropopause temperature, (b) upper tropospheric stability, (c) vertical velocity at $500 \mathrm{hPa}$, and (d) lower tropospheric stability. The region covered by this SST regime only extends to $\sim 70^{\circ}$. We will examine the polar regions separately in section 3.6.

As is the case in the deep convective regime, upper tropospheric cloud incidence is strongly linked to tropopause temperature (Figure 5a) and upper tropospheric stability (Figure 5b) throughout the middle/ high latitudes. This feature indicates that the intrinsic relationships between tropopause temperature, upper tropospheric stability, and vertical motion as noted in the deep convective regime are also applicable to the middle-/high-latitude regime. Between 6 and $12 \mathrm{~km}$, middle-/high-latitude cloud incidence increases by $1.5-2 \% \mathrm{~K}^{-1}$ as tropopause temperatures decrease from 220 to $205 \mathrm{~K}$, and by $\sim 8 \%$ per $\mathrm{K} \mathrm{km}^{-1}$ as upper tropospheric stability decreases from 5 to $1 \mathrm{~K} \mathrm{~km}^{-1}$. In general, colder tropopause temperatures correspond to a lifting of the tropopause and thus increase in tropospheric cloud incidence, and vice versa. The results suggest that any physical process that acts to lift or depress the tropopause-including stratospheric processes [e.g, Li and Thompson, 2013] — can project onto tropospheric cloud incidence.

The vertical structure of cloud incidence as a function of vertical velocity (Figure $5 c$ ) exhibits two distinct maxima: (1) between 6 and $10 \mathrm{~km}$ in regions of maximum ascent and (2) below $3 \mathrm{~km}$ in regions of moderate descent. Between 6 and $10 \mathrm{~km}$, cloud incidence increases as a function of vertical motion at a rate of $1 \%$ per $10 \mathrm{hPa} \mathrm{d}^{-1}$. Below $3 \mathrm{~km}$, cloud incidence peaks in regions of descent of $\sim 20 \mathrm{hPa} \mathrm{d}^{-1}$, and cloud top is capped within the boundary layer. The relationships between cloud incidence and large-scale vertical motion at 


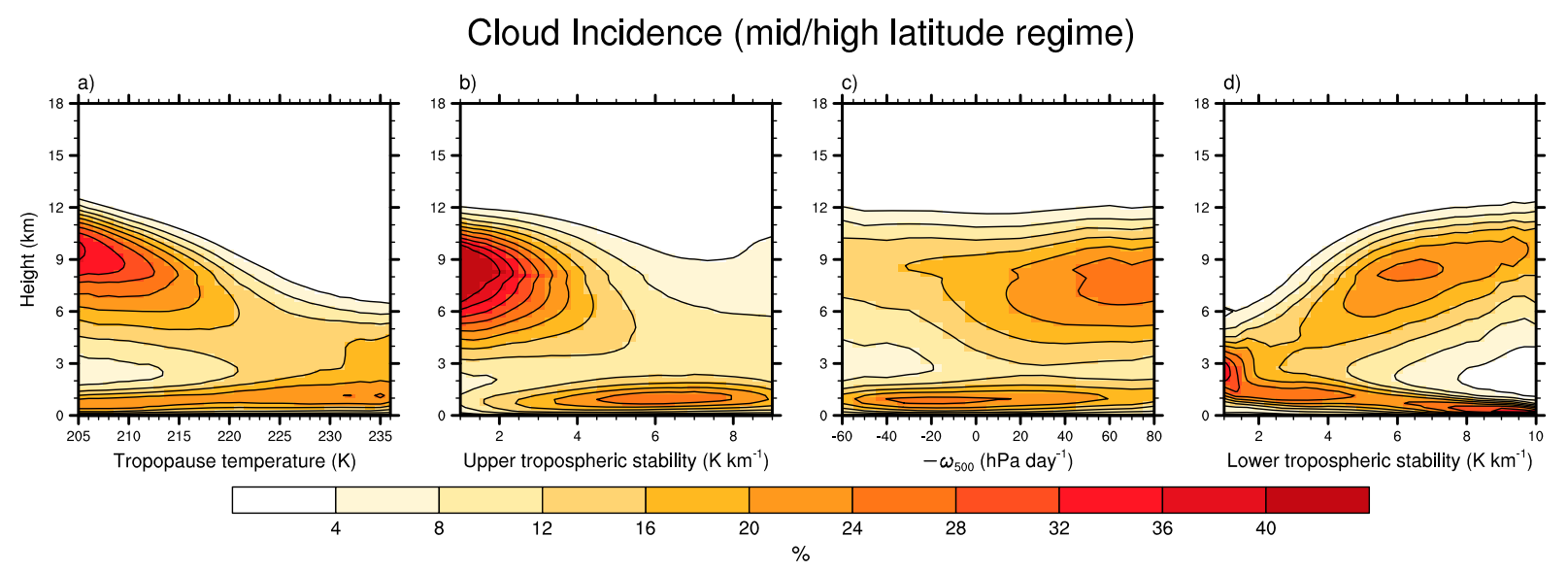

Figure 5. Vertical distribution of cloud incidence as a function of (a) tropopause temperature, (b) upper tropospheric stability, (c) $-\omega_{500}$, and (d) lower tropospheric stability in the middle-/high-latitude regime.

$500 \mathrm{hPa}$ are consistent with previous studies [Lau and Crane, 1995, 1997; Tselioudis et al., 2000; Lin, 2004]: High-top clouds tend to occur in regions of low pressure and large-scale upward motion; low-top clouds tend to occur in regions of high pressure and sinking motion. The results suggest that the bimodal vertical distribution of clouds in both the Northern Hemisphere middle/high latitudes (as shown here) and over the Southern Ocean [Verlinden et al., 2011] is due to the superposition of alternating cyclonic and anticyclonic weather systems. It can be also due to the passage of the cold frontal system with upper level clouds in regions of rising motion ahead of the cold front and low-level clouds in regions of sinking motion behind the cold front.

Low-level cloud incidence is also linked to lower tropospheric stability (Figure $5 \mathrm{~d}$ ). Cloud incidence in the boundary layer exhibits two distinct peaks: one in regions of high near-surface static stability and one in regions of very low near-surface static stability. The rate of increase in cloud incidence as a function of static stability in regions of high static stability is roughly 4 times weaker than it is in the subtropical regime (Figure 4b). The dual maxima in low-level cloud incidence evident in Figure $5 \mathrm{~d}$ is consistent with the presence of very different cloud types throughout the middle/high latitudes. The maximum at low values of static stability is consistent with stratus associated with extratropical synoptic storms [Norris, 1998]; the maximum at high values of static stability is consistent with stratocumulus clouds over the North Pacific and North Atlantic [Klein and Hartmann, 1993].

\subsection{Midlatitude Storm Track Region}

Cloud type, optical depth, and cloud-top height over the midlatitude ocean are also strongly influenced by synoptic-scale dynamic and thermodynamic conditions in the vicinity of the storm track [e.g., Lau and Crane, 1995; Norris and lacobellis, 2005]. The structure of clouds and other environmental properties associated with midlatitude cyclones have been investigated in a series of studies using satellite data [Lau and Crane, 1995, 1997; Klein and Jakob, 1999; Naud et al., 2006; Field and Wood, 2007; Posselt et al., 2008; Naud et al., 2010]. In this section, we examine the relationships between cloud incidence and two environmental parameters in the storm track region: the variance of vertical motion and the meridional gradient of the SST.

Figure 6 shows the long-term mean amplitude of storm track activity, defined here as the RMS of daily 500 $\mathrm{hPa}$ vertical velocity $\left[\left(\overline{\omega^{\prime 2}}\right)^{1 / 2}\right.$; see section 2]. The RMS of vertical motion is organized into distinctive bands centered over the North Pacific, North Atlantic, South Pacific, and South Atlantic. All four regions are consistent with the climatological mean position of the midlatitude storm tracks [e.g., Blackmon et al., 1984; Wallace et al., 1988; Trenberth, 1991].

Figure 7a quantifies the linkages between cloud incidence and the RMS of vertical motion in the four midlatitude storm track regions defined by the boxes in Figure 6. The results are based on combined data from all four storm track regions; analyses based on individual storm track regions (not shown) yield very similar results. As is the case for the midlatitudes as a whole (Figure 5), cloud incidence in the storm track regions exhibits two distinct peaks: one near the surface and one near the jet stream level at $250 \mathrm{hPa}$ level 


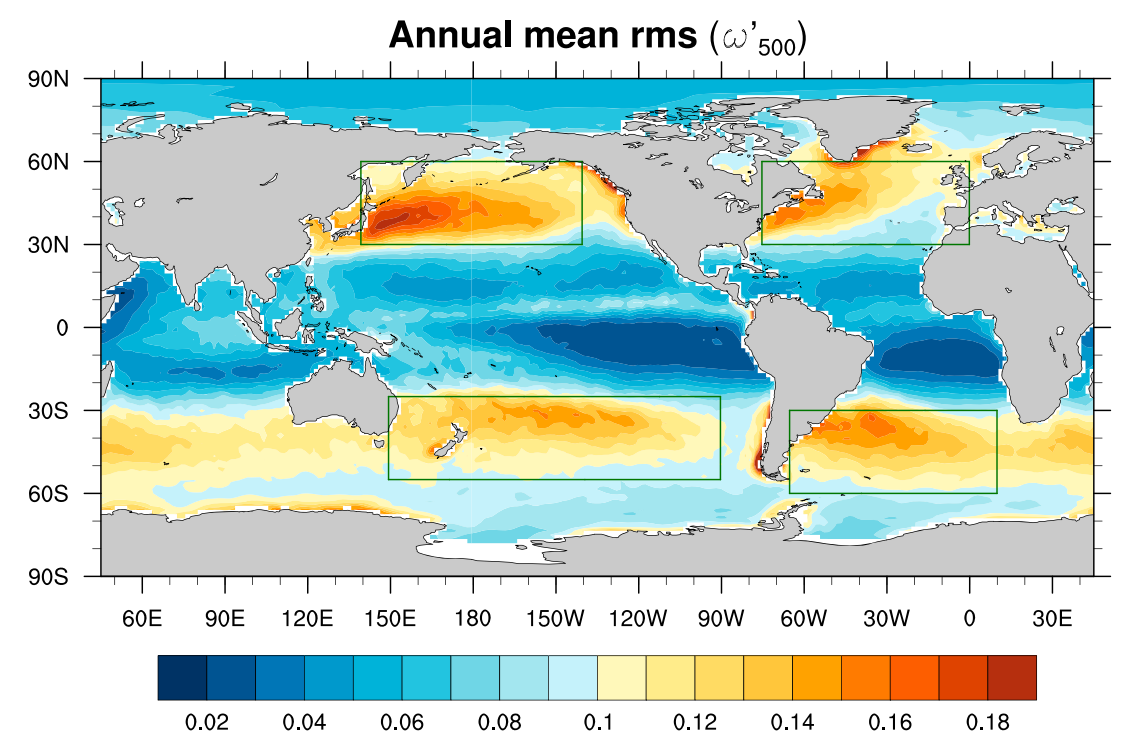

Figure 6. Same as in Figure 1 but for the root-mean-square (RMS) of daily deviations of $\omega_{500}$. The rectangular outlines depict the North Pacific $\left(30^{\circ}-60^{\circ} \mathrm{N}, 140^{\circ} \mathrm{E}-140^{\circ} \mathrm{W}\right)$, North Atlantic $\left(30^{\circ}-60^{\circ} \mathrm{N}, 75^{\circ} \mathrm{W}-0^{\circ}\right)$, South Pacific $\left(55^{\circ}-25^{\circ} \mathrm{S}\right.$, $\left.150^{\circ} \mathrm{E}-90^{\circ} \mathrm{W}\right)$, and South Atlantic $\left(60^{\circ}-30^{\circ} \mathrm{S}, 65^{\circ} \mathrm{W}-10^{\circ} \mathrm{E}\right)$ storm track regions. These are the four regions for constructing the plots in Figure 7.

( 9-10 km). Cloud incidence at upper levels increases by $4 \%$ per $0.1 \mathrm{hPa} \mathrm{d}^{-1}$ as the RMS of vertical motion increases from 0.1 to $0.2 \mathrm{hPa} \mathrm{d}^{-1}$ (Figure 7a). In contrast, cloud incidence at lower levels decreases with increasing storm track amplitude. The positive correlation between storm track activity and upper tropospheric cloud incidence is consistent with increased nimbostratus and deep convective clouds during periods of enhanced synoptic activity [e.g., Lau and Crane, 1995; Weaver and Ramanathan, 1996, 1997; Gordon et al., 2005]. The negative correlation between storm track activity and near-surface cloud incidence is consistent with anticyclonic conditions and thus anomalously high low-level static stability during quiescent periods in the extratropical storm tracks.

Cloud Incidence in the combined four storm track regions

a)

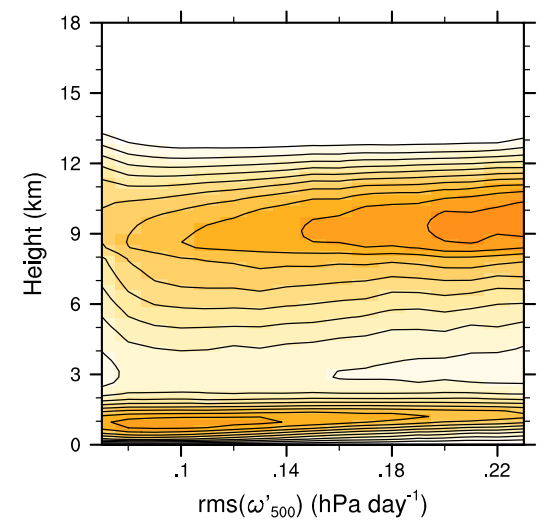

b) $8-11 \mathrm{~km}$

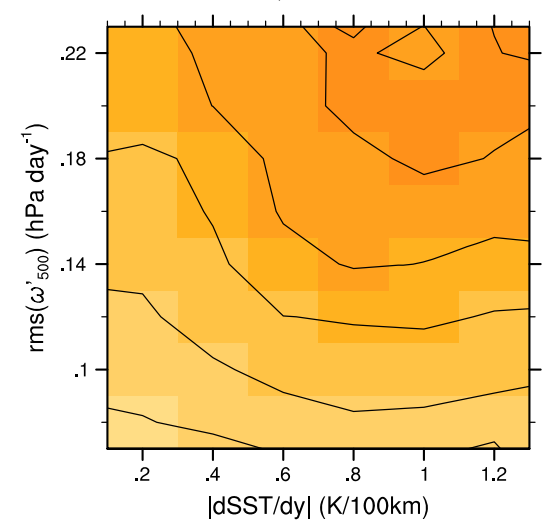

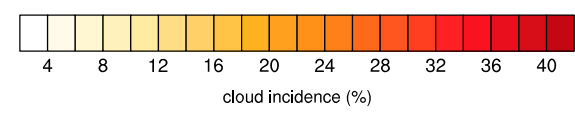

Figure 7. (a) Vertical distribution of cloud incidence as a function of $\left(\overline{\omega^{\prime}}\right)^{1 / 2}$ and (b) cloud incidence averaged between 8 and $11 \mathrm{~km}$ as a function of meridional SST gradient $(\mathrm{K} / 100 \mathrm{~km})$ and $\left(\omega^{\prime 2}\right)^{1 / 2}$ over the four midlatitude storm track regions as denoted in Figure 6. 


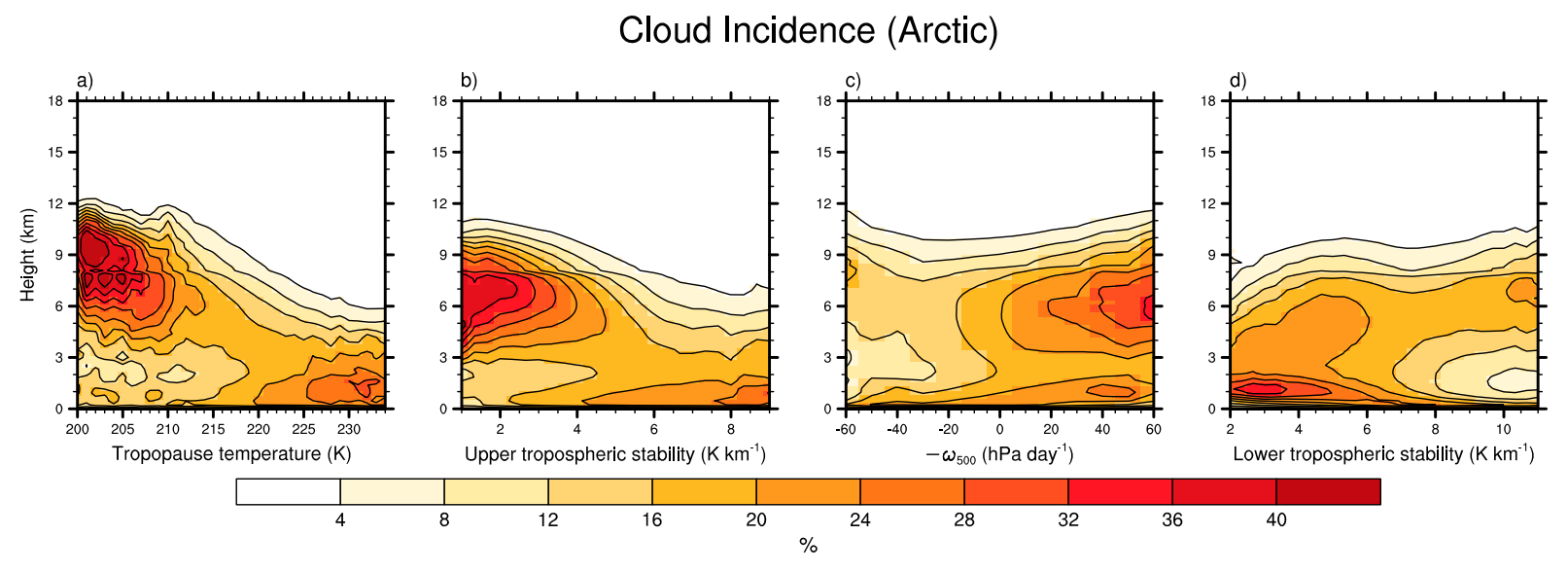

Figure 8. Same as Figure 5 but for the Arctic region northward of $70^{\circ} \mathrm{N}$.

The amplitude of the extratropical storm track is related to the growth rate of baroclinic waves and thus surface baroclinicity [e.g., Lindzen and Farrell, 1980]. It is hence also proportional to the meridional gradient of the SST [e.g., Kushnir et al., 2002, and references therein; Brayshaw et al., 2008]. Figure 7b examines upper tropospheric $(8-11 \mathrm{~km}$ ) cloud incidence as a function of both the meridional gradient in SST (abscissa) and storm track activity (ordinate). The results provide insight into the components of the linkages between storm track activity and cloud incidence that are linearly independent of the SST field, and vice versa. Cloud incidence at a fixed value in the meridional gradient in SST increases monotonically with increasing storm track activity. This is particularly true for SST gradients between 0.6 and $1.2 \mathrm{~K} / 100 \mathrm{~km}$. Conversely, incidence at a fixed amplitude of storm track activity peaks for SST gradients centered around $1 \mathrm{~K} / 100 \mathrm{~km}$. Cloud incidence is thus a strong function of the surface baroclinicity even when the amplitude of the overlying synoptic activity is held fixed.

\subsection{Arctic Region}

The structure of clouds over the Arctic depends on many atmospheric dynamic and thermodynamic conditions, such as air temperature, sea level pressure, low-level moisture advection, large-scale vertical motion, and lower tropospheric stability [e.g., Curry et al., 1996; Morrison and Pinto, 2005; Kay and Gettelman, 2009; Eastman and Warren, 2010; Barton et al., 2012]. It is also a function of sea ice concentration [e.g., Kay and Gettelman, 2009; Palm et al., 2010; Eastman and Warren, 2010; Kay et al., 2011; Wu and Lee, 2012; Sato et al., 2012]. Figure 8 quantifies the linkages between cloud incidence over the Arctic and four atmospheric parameters. The Arctic is defined as the region poleward of $70^{\circ} \mathrm{N}$ (including sea ice regions). As for the other regimes, we focus on large-scale vertical motion at $500 \mathrm{hPa}$, but the results are not sensitive to the specific level chosen for the analyses (e.g., similar results are derived for $600 \mathrm{hPa}$, not shown).

The linkages between upper tropospheric cloud incidence, tropopause temperature, and upper tropospheric stability (Figures $8 \mathrm{a}$ and $8 \mathrm{~b}$ ) are very similar to those found in the middle-/high-latitude regime (Figures $5 \mathrm{a}$ and $5 \mathrm{~b}$ ). Higher tropopause temperatures correspond to depression of the tropopause, increased static stability, and thus inhibited upward motion. As such, upper tropospheric cloud incidence decreases with both increasing tropopause temperature and increasing upper tropospheric stability. The rate of decreasing cloud incidence with increasing tropopause temperature and upper tropospheric stability is $2 \% \mathrm{~K}^{-1}$ and $5 \%$ per $\mathrm{K} \mathrm{km}^{-1}$, respectively. It should be noted that a weak discontinuity is apparent near $\sim 8 \mathrm{~km}$. The discontinuity is restricted to latitudes north of $75^{\circ} \mathrm{N}$ and is likely due to the change in the resolution of CALIPSO data and a drop in the sensitivity of the lidar at $8.2 \mathrm{~km}$ [Winker et al., 2009, 2010]. Indeed, a similar discontinuity in cloudiness near $8 \mathrm{~km}$ has also been found in the Southern Hemisphere south of $75^{\circ} \mathrm{S}$ based on the CloudSat and CALIPSO observations [cf. Verlinden et al., 2011, Figure 4; Bromwich et al., 2012, Figure 9].

Middle and upper tropospheric polar cloud incidence is also strongly linked to large-scale vertical motion at $500 \mathrm{hPa}$ (Figure 8c). In the free troposphere between $\sim 4$ and $9 \mathrm{~km}$, cloud incidence increases with increasing rising motion at a rate of $\sim 2 \%$ per $10 \mathrm{hPa} \mathrm{d}^{-1}$. In contrast to the subtropical and middle latitude regimes (Figures $4 \mathrm{a}$ and $5 \mathrm{c}$ ), clouds at Arctic surface increase with increasing vertical motion in the free troposphere 


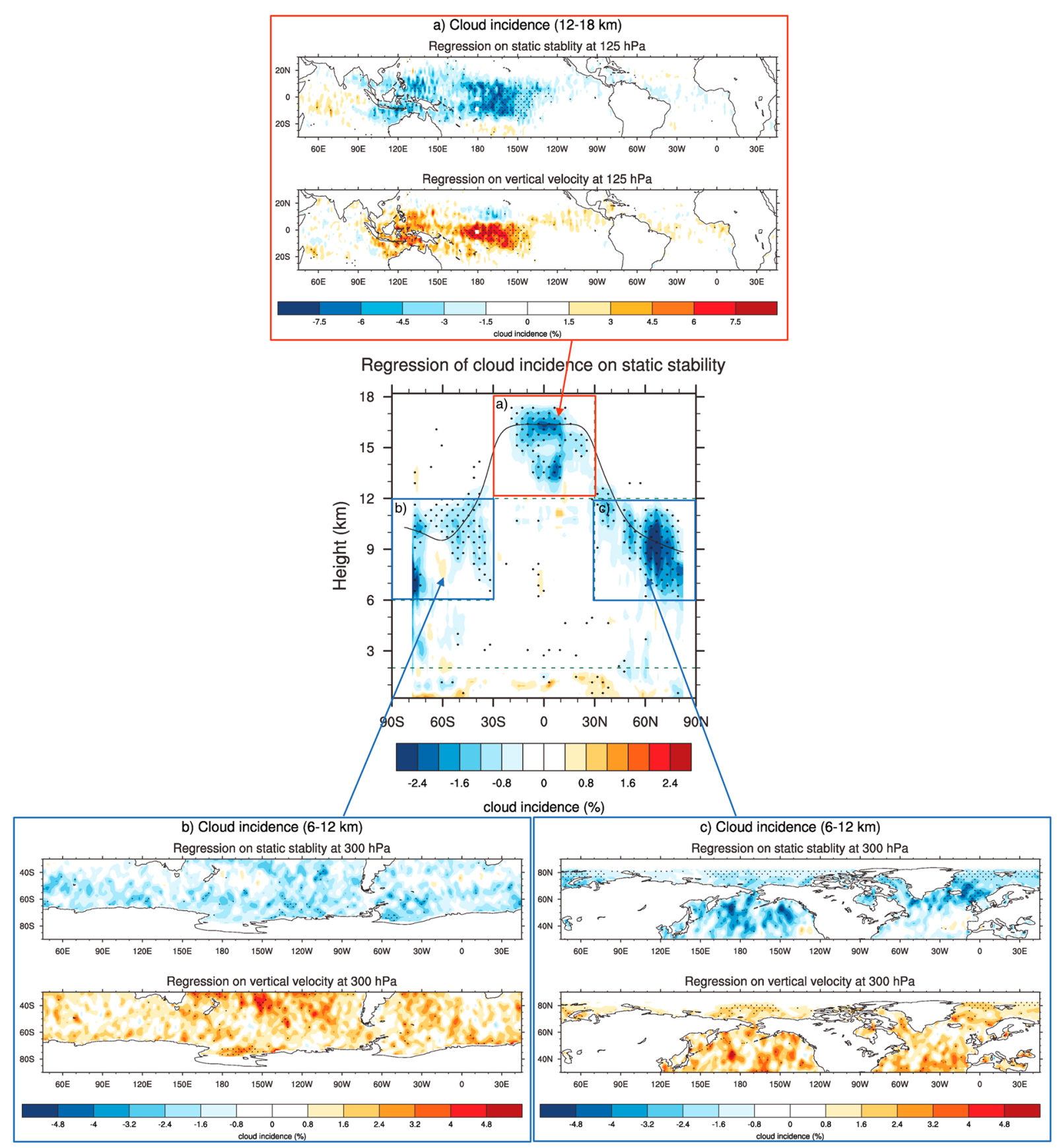

Figure 9. (middle) Regressions of monthly mean zonal mean cloud incidence onto standardized monthly mean zonal mean anomalous static stability as a function of latitude and height. (a) Regressions of monthly mean cloud incidence averaged between 12 and 18 onto standardized monthly mean anomalous (top) static stability and (bottom) vertical motion at $125 \mathrm{hPa}$. (b and c) Regressions of monthly mean cloud incidence averaged between 6 and 12 onto standardized monthly mean anomalous (top) static stability and (bottom) vertical motion at $300 \mathrm{hPa}$. Static stability $(\partial \theta / \partial z)$ in the middle panel is based on ECMWF-AUX product. Static stability $(\partial \theta / \partial z)$ and vertical motion $(-\omega)$ in the external panels are based on the ERA-Interim reanalysis.

(Figure 8c). The influence of large-scale vertical motion on Arctic cloud formation inferred from previous studies is inconclusive. Some studies have argued that large-scale vertical velocity is relatively unimportant for the formation and maintenance of Arctic stratus clouds [Pinto, 1998]; others have argued that vertical motion is key for the formation of low- and middle-level Arctic clouds [Curry et al., 1996; Morrison and Pinto, 2005; Zuidema et al., 2004; Zhao and Wang, 2010]. Using the CloudSat and CALIPSO observation, our results reveal that large-scale vertical motion exerts a strong influence on the incidence of clouds in the Arctic at both low and middle levels. 
Boundary layer cloud incidence increases markedly in regions with weak lower tropospheric static stability (Figure $8 \mathrm{~d}$ ) at a rate of $4 \%$ per $\mathrm{K} \mathrm{km}^{-1}$. Again, this is in contrast to the subtropical and middle latitude regimes, where boundary layer cloud incidence increases in regions with high lower tropospheric stability (Figures $4 b$ and $5 d$ ). The out-of-phase relationship between low-level clouds and lower tropospheric stability in the Arctic is consistent with the seasonal cycle of cloudiness there. Klein and Hartmann [1993] note that low-level cloud incidence peaks over the Arctic during summer when lower tropospheric static stability is weakest. The linkages between lower tropospheric static stability and cloud incidence over the Arctic are thought to arise from increases in the upward turbulent fluxes of moisture and heat as the boundary layer becomes increasingly unstable [see Kay and Gettelman, 2009, and references therein]. Note that the thickness of the Arctic boundary cloud layer is increasingly shallow as lower tropospheric stability increases. Note that cloud incidence also increases above the boundary layer in regions with weak lower tropospheric stability.

\section{Observed Linkages Between the Vertical Structures of Cloud Incidence and the Meteorology: Month-to-Month Variability}

In the previous section, we examined the linkages between cloud incidence and various large-scale meteorological parameters in the long-term mean. In this section, we will build on the results shown in the previous section to interpret the relationships between cloud incidence and the large-scale meteorology on month-to-month timescales. All results in this section are based on anomalous data (i.e., the annual cycle has been removed from the data). We will first examine to what extent the instantaneous linkages between static stability and cloud incidence found in the long-term mean extend to month-to-month timescales.

Figure 9 (middle) explores the linkages between zonal mean static stability and cloud incidence on month-to-month timescales. The shading in Figure 9 (middle) shows monthly mean, zonal mean cloud incidence anomalies regressed onto standardized values of the anomalous monthly mean, zonal mean static stability as a function of latitude, and height. For example, the regression coefficient at $5^{\circ} \mathrm{N}$ and $16 \mathrm{~km}$ corresponds to the regression of zonal mean cloud incidence anomalies at $5^{\circ} \mathrm{N}$ and $16 \mathrm{~km}$ onto standardized values of the static stability anomalies at $5^{\circ} \mathrm{N}$ and $16 \mathrm{~km}$. The solid black line indicates the long-term mean tropopause height. In this plot (and other plots to follow), stippling indicates results that are $95 \%$ significant based on a two-tailed test of the $t$ statistic with an effective sampling size given by Bretherton et al. [1999, equation (31)].

The most pronounced feature in Figure 9 (middle) is the negative relationship between static stability and cloud incidence anomalies in the upper troposphere and lower stratosphere. Periods of enhanced local static stability are associated with reduced cloud incidence anomalies, with anomalies peaking between $\sim 12$ and $18 \mathrm{~km}$ in tropical latitudes and $\sim 6-12 \mathrm{~km}$ in the middle and high latitudes of both hemispheres. The regression coefficients are positive in the lowermost troposphere, but the zonal mean results are relatively weak there. As shown below, the linkages between cloud incidence and static stability in the lowermost troposphere are much more clear in latitude/longitude sections.

4.1. Upper Troposphere and Lower Stratosphere

4.1.1. Horizontal Structure

The external panels in Figure 9 examine the horizontally varying relationships between month-to-month variability in the meteorology and cloud incidence in three regions where the linkages between zonal mean cloud incidence and static stability (Figure 9, middle) are most robust: (1) in the tropics between 12 and $18 \mathrm{~km}$ (Figure 9a), (2) in the Southern Hemisphere (SH) between 6 and $12 \mathrm{~km}$ (Figure 9b), and (3) in the Northern Hemisphere (NH) between 6 and 12 km (Figure 9c).

The results in Figure 9a show the regression of monthly mean cloud incidence anomalies vertically averaged between 12 and $18 \mathrm{~km}$ in the tropics onto standardized values of monthly mean static stability (Figure 9a, top) and vertical motion (Figure 9a, bottom) at $125 \mathrm{hPa}$. The regression coefficients are calculated for each $1.5^{\circ}$ (longitude) $\times 1.5^{\circ}$ (latitude) grid box, and then light horizontal smoothing is applied to the results for the purpose of display only. The $125 \mathrm{hPa}$ level ( $15 \mathrm{~km}$ above the ocean surface in the tropics) is chosen as it corresponds roughly to the middle of the cloud layer between 12 and $18 \mathrm{~km}$ in the tropics. The results in Figures $9 \mathrm{~b}$ and $9 \mathrm{c}$ show analogous regression coefficients but for the upper troposphere/lower stratosphere 
in the SH (left) and NH (right) middle/high latitudes. In these cases, cloud incidence is averaged between 6 and $12 \mathrm{~km}$ (roughly 450-200 hPa), and the static stability and vertical motion are sampled at $300 \mathrm{hPa}$.

The results in Figures 9a-9c indicate the following primary relationships between month-to-month variability in upper tropospheric/lower stratospheric cloud incidence and the background meteorology.

1. Throughout much of the globe, periods of anomalously low static stability and upward vertical motion are associated with anomalously high cloud incidence. The linkages are most pronounced in the western tropical Pacific, where a 1 standard deviation decrease in static stability/increase in vertical motion is associated with $5 \%$ increase in cloud incidence. The region of negative correlation between vertical motion and upper tropospheric cloud incidence north of the equatorial central Pacific (Figure 9a, bottom) clearly warrants further investigation but is beyond the scope of this study.

2. The tropical linkages exhibit notable zonal asymmetry consistent with the signatures of the equatorial planetary waves [e.g., Dima and Wallace, 2007] and zonal shifts of convection during ENSO events [e.g., Gettelman et al., 2001; Virts and Wallace, 2010]. The correlations near the dateline peak near $r \approx 0.6$ (not shown). Thus, variations in grid-box scale static stability and vertical motion (i.e., averaged over a $1.5^{\circ} \times 1.5^{\circ}$ grid box as opposed to within individual convective plumes) account for $\sim 35 \%$ of the month-to-month variability in cloud incidence between 12 and $18 \mathrm{~km}$.

3. The extratropical linkages are zonally symmetric and have slightly lower amplitude than their tropical counterparts. Throughout much of the extratropical $\mathrm{NH}$ and $\mathrm{SH}$, variations in grid-box scale static stability and vertical motion account for $\sim 20-30 \%$ of the month-to-month variability in cloud incidence between 6 and $12 \mathrm{~km}$. The results in Figures $9 \mathrm{~b}$ and $9 \mathrm{c}$ are consistent with those reported in Li and Thompson [2013], who note that the changes in static stability associated with the stratospheric Brewer-Dobson circulation account for more than $30 \%$ of the month-to-month variability in cloudiness in both the tropical tropopause transition layer and Arctic middle-upper troposphere.

\subsubsection{Vertical Structure}

Figure 10 explores the vertical structure of the linkages between anomalous cloud incidence, static stability, and vertical motion over the tropical and extratropical oceans. The results in Figure 10 are constructed in a similar manner to Figures 2-5, except that the seasonal cycle has been removed from the cloud incidence and meteorological data before computing the scatterplots. We are unaware of any other study that examines the anomalous CloudSat data as a function of a range of anomalous meteorological parameters. Figures $10 \mathrm{a}$ and $10 \mathrm{~b}$ show the vertical distribution of the cloud incidence anomalies as a function of anomalous $125 \mathrm{hPa}$ static stability (Figure 10a) and vertical motion (Figure 10b) over the tropical ocean (i.e., the relationships are averaged over all grid boxes $30^{\circ} \mathrm{S}-30^{\circ} \mathrm{N}$ ). Figures $10 \mathrm{c}$ and $10 \mathrm{~d}$ show analogous results for the anomalous $300 \mathrm{hPa}$ static stability (Figure 10c) and vertical motion (Figure 10d) over the extratropical oceans (i.e., the relationships are averaged over all grid boxes $30-90^{\circ} \mathrm{S}$ and $30-90^{\circ} \mathrm{N}$ ). The results in Figure 10 are derived from more than $4 \times 10^{5}$ profiles over the tropical ocean and $\sim 7 \times 10^{5}$ profiles over the extratropical ocean.

In the tropics (Figures 10a and 10b), regions of anomalously low static stability and anomalous upward motion at $125 \mathrm{hPa}$ are associated with anomalously large cloud incidence between $\sim 13$ and $18 \mathrm{~km}$, and vice versa. Cloud incidence at $\sim 16 \mathrm{~km}$ decreases with increasing $125 \mathrm{hPa}$ static stability at a rate of $\sim 2-3 \%$ per $\mathrm{K} \mathrm{km}^{-1}$ and increases with the increasing $125 \mathrm{hPa}$ upward motion at a rate of $\sim 7 \%$ per $10 \mathrm{hPa} \mathrm{d}^{-1}$. Interestingly, the anomalies in cloud incidence are noticeably larger in regions of anomalous upward motion than they are in regions of anomalous downward motion (Figure 10b).

Similar linkages are found in the extratropics (Figures 10c and 10d). Regions of anomalously low static stability and upward motion at $300 \mathrm{hPa}$ are associated with anomalously high cloud incidence between $\sim 6$ and $12 \mathrm{~km}$, and vice versa. Cloud incidence at $\sim 9 \mathrm{~km}$ decreases with increasing $300 \mathrm{hPa}$ static stability at a rate of $2 \%$ per $\mathrm{K} \mathrm{km}^{-1}$ and increases with the increasing $300 \mathrm{hPa}$ vertical motion at a rate of $\sim 3 \%$ per $10 \mathrm{hPa} \mathrm{d}^{-1}$. The differences in cloud incidence anomalies for regions of anomalous upward and downward motion are less pronounced than they are in the tropics.

The cloud incidence anomalies based on anomalous upper tropospheric static stability exhibit marked vertical dipoles (Figures 10a and 10c). The dipoles in cloud incidence are consistent with the attendant pattern in anomalous vertical motion, i.e., a similar vertical dipole is found when vertical motion anomalies are binned as a function of anomalous upper tropospheric static stability (not shown). 


\section{Cloud Incidence anomalies}
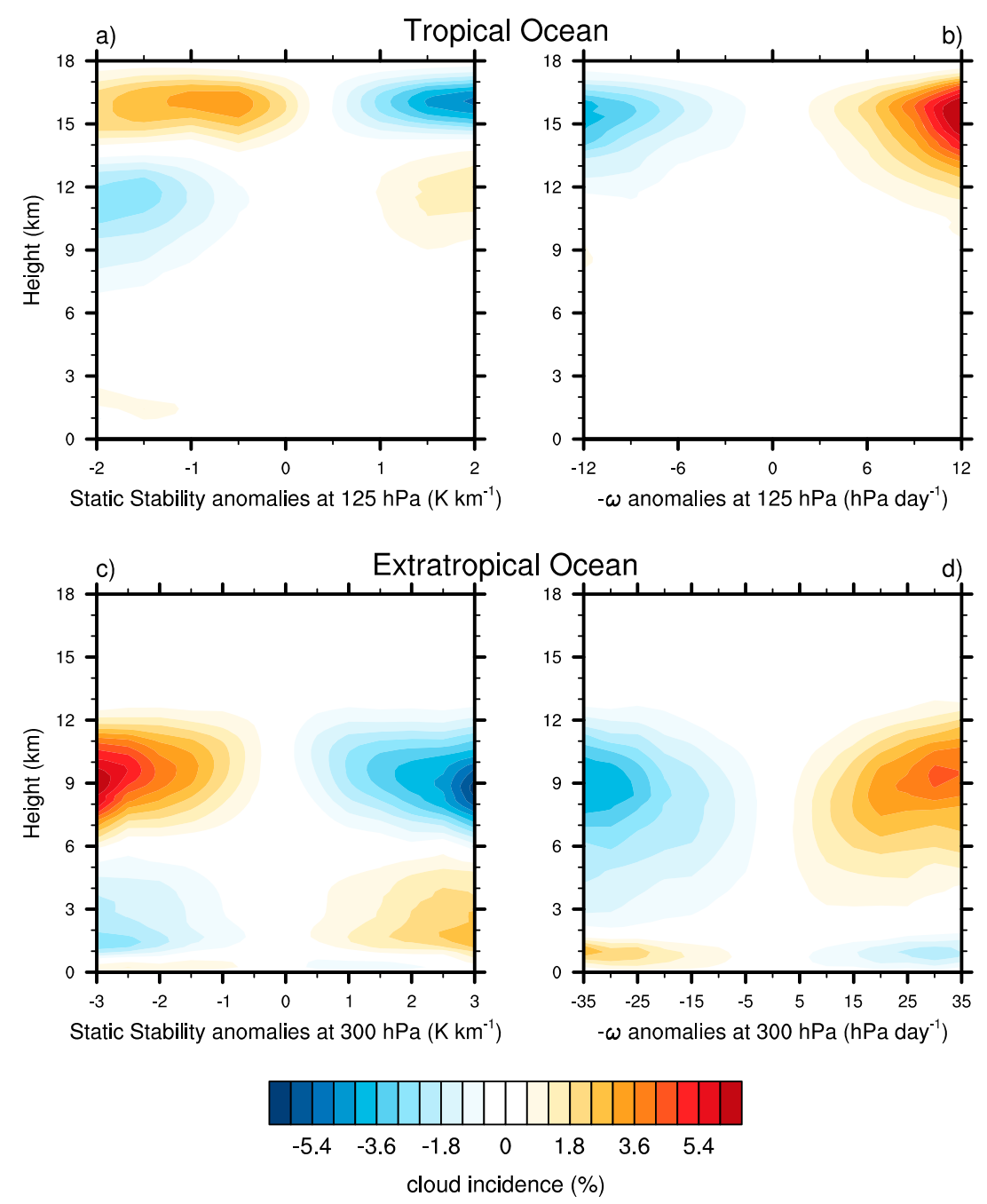

Figure 10. Vertical distribution of monthly mean cloud incidence anomalies as a function of monthly mean anomalous of (a) upper tropospheric stability at $125 \mathrm{hPa}$ and (b) vertical motion at $125 \mathrm{hPa}$ over the tropical ocean $\left(30^{\circ} \mathrm{S}-30^{\circ} \mathrm{N}\right)$. Vertical distribution of monthly mean cloud incidence anomalies as a function of monthly mean anomalous of (c) upper tropospheric stability at $300 \mathrm{hPa}$ and (d) vertical motion at $300 \mathrm{hPa}$ over the extratropical ocean (poleward of $30^{\circ}$ ).

\subsection{Lowermost Troposphere}

Figure 11 shows cloud incidence averaged between 0 and $3 \mathrm{~km}$ regressed onto lower tropospheric static stability (Figure 11a; see definition in section 2) and vertical velocity at $700 \mathrm{hPa}$ (Figure 11b). Over much of the ocean equatorward of $\sim 50^{\circ}$ latitude, periods of enhanced lower troposphere static stability and downward motion at $700 \mathrm{hPa}$ are marked by anomalously large cloud incidence, with distinct maxima found over the eastern subtropical Pacific ocean and in the vicinity of the Pacific equatorial cold tongue (Figure 11a). The largest positive cloud incidence anomalies are found in regions dominated by subtropical marine boundary layer clouds [e.g., Klein and Hartmann, 1993; Norris and Leovy, 1994]. The large regression coefficients over the northeastern side of the NH ocean basins are consistent with results shown in Kubar et al. [2012], who note that cloud fraction derived from Moderate Resolution Imaging Spectroradiometer Aqua is positively correlated with static stability over the northeastern Pacific and northeastern Atlantic but weakly negatively correlated with static stability over the northwestern side of both basins.

The relationships between static stability and lower tropospheric cloud incidence are the opposite sign over subpolar and polar latitudes. Consistent with the relationships observed in the long-term mean (section 3), 

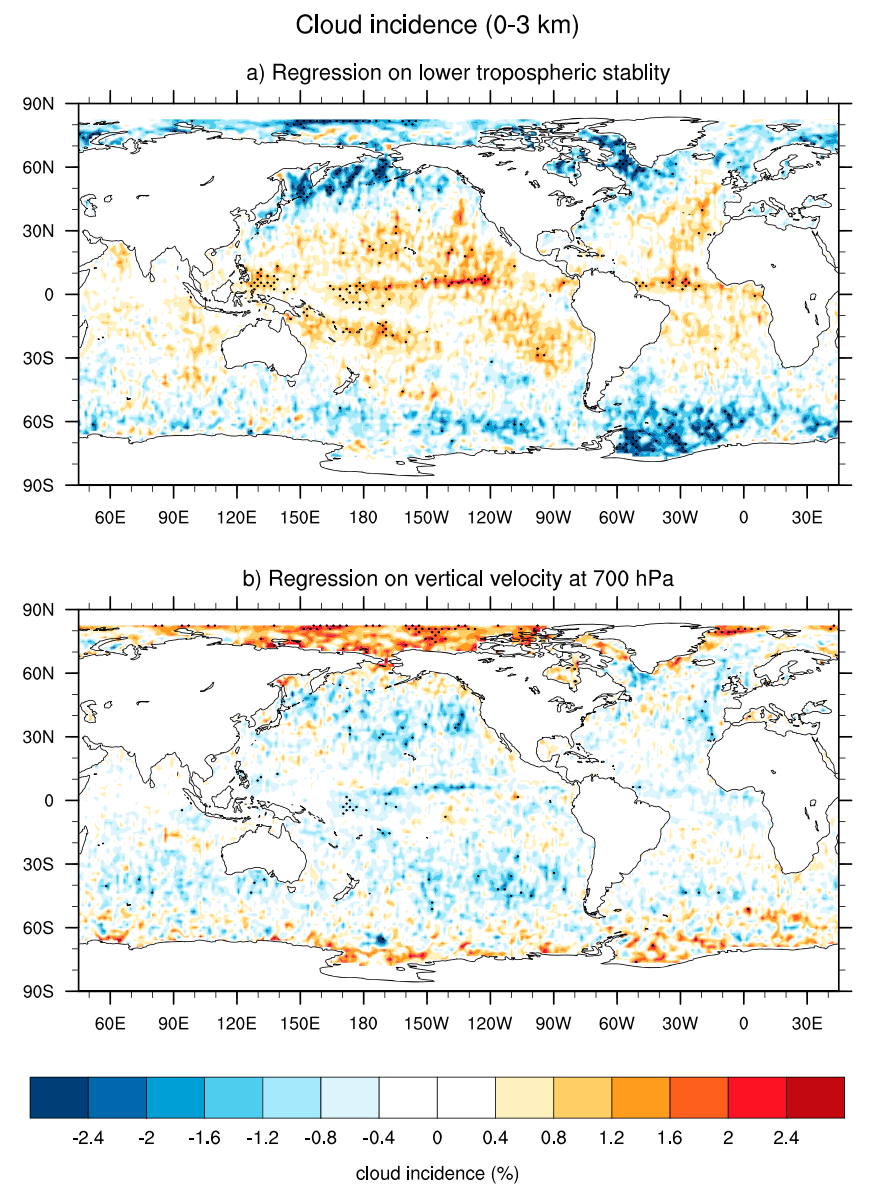

Figure 11. Regressions of monthly mean cloud incidence averaged between 0 and 3 onto standardized monthly mean anomalous (top) lower tropospheric stability (see definition in section 2) and (bottom) vertical motion at $700 \mathrm{hPa}$.

periods of enhanced lower tropospheric stability and downward motion are marked by reduced cloud incidence anomalies over the Arctic and the subpolar Southern Ocean.

\section{Summary and Discussion}

This is the second in a series of studies that explores the linkages between large-scale atmospheric dynamics and the vertical structure of cloud incidence using the CloudSat data. Li and Thompson [2013] examine the signature of the stratospheric Brewer-Dobson circulation in tropospheric cloudiness. The current study explores and quantifies the instantaneous linkages between the vertical structure of cloud incidence and various meteorological parameters throughout the global ocean in the long-term mean and on month-to-month timescales. A third study [Li et al., 2013] applies the linkages documented here to interpret the signature of large-scale patterns of dynamic variability in cloud incidence and cloud radiative forcing.

The results in the current study confirm and support previous work on the linkages between the meteorology and cloud incidence (as reviewed in section 1). But the current study is also novel in several important ways: (1) it provides a systematic survey of the linkages between cloud incidence and the meteorology at all levels of the troposphere throughout all areas of the global ocean; (2) it provides quantitative estimates of many relationships averaged over upward of $\sim 1 \times 10^{8}$ individual profile measurements (i.e., the relationships are not calculated from monthly mean versions of the data-as done in some previous studies-but rather from individual profile measurements); (3) it explores the relationships not only in the long-term mean but also on month-to-month and interannual timescales; and (4) it explores the signatures in cloud incidence of meteorological parameters not widely considered in previous work, including tropopause temperatures, upper tropospheric stability, and storm track activity. 

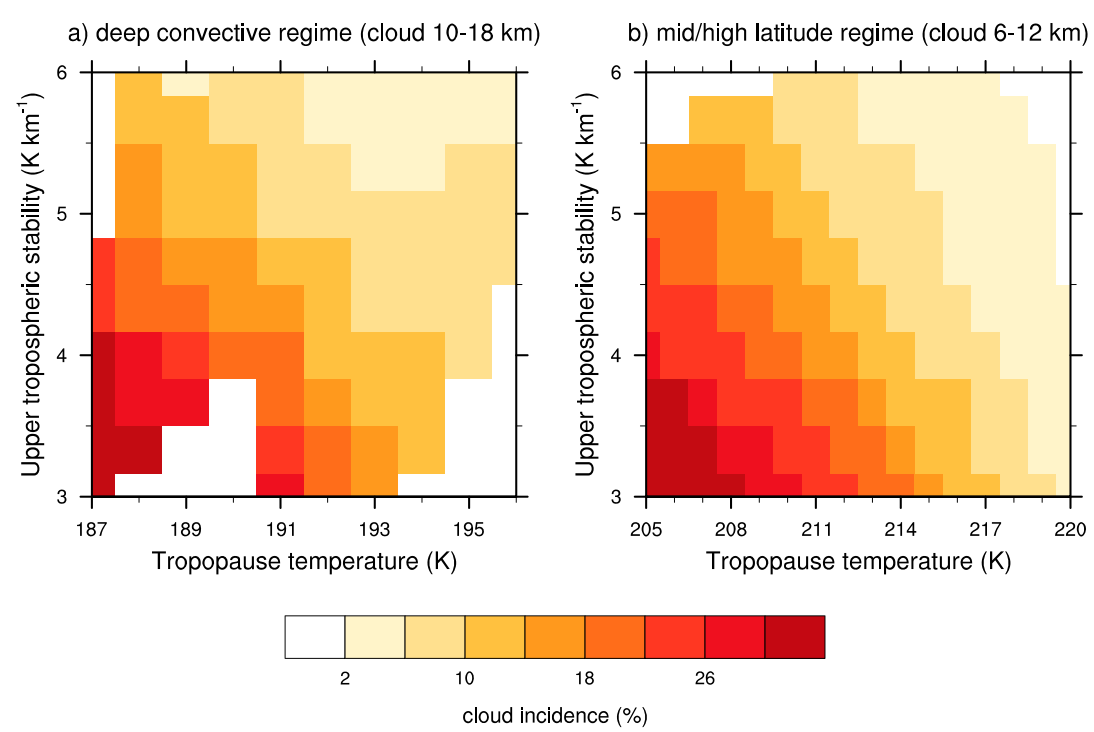

Figure 12. Cloud incidence as a function of tropopause temperature and upper tropospheric stability. Results are shown for cloud incidences averaged between (a) 10-18 km in the deep convective regime and (b) 6-12 km in the middle-/high-latitude regime.

The vertical structure of cloud incidence is investigated here in three regimes defined by the underlying distribution of sea surface temperatures (Figure 2): (1) the "deep convective regime" (SSTs greater than $300 \mathrm{~K}$ ), (2) the "subtropical regime" (SSTs between 286 and $300 \mathrm{~K}$ ), and (3) the "middle-/high-latitude regime" (SSTs between 272 and $286 \mathrm{~K}$ ). We also investigated the vertical structure of cloudiness over the Arctic. The primary findings are as follows:

1. Influence of thermodynamic and dynamic conditions in the upper troposphere. Tropopause temperature and upper tropospheric stability reflect the thermodynamic and dynamic upper boundary conditions on tropospheric clouds. Tropopause temperatures provide a measure of conditions at the interface with the stratosphere, much as SSTs provide a measure of conditions at the interface with the ocean. They are strongly linked to the incidence of clouds in the upper troposphere throughout the global ocean via their influence on vertical motion. That is, decreases in tropopause temperature are associated with decreases in upper tropospheric stability and thus enhanced vertical motion. Our results not only establish the robustness of the linkages between tropopause temperatures, upper tropospheric static stability, and cloud incidence but also demonstrate that they extend to most regions of the global ocean.

In the long-term mean, cloud incidence increases with decreasing tropopause temperature and upper tropospheric stability at rates of $\sim 2-4 \% \mathrm{~K}^{-1}$ and $\sim 5-10 \%$ per $\mathrm{K} \mathrm{km}^{-1}$, respectively. Variations in static stability and vertical motion account for $\sim 35 \%$ and $\sim 20 \%$ of the month-to-month variability in upper tropospheric cloudiness at tropical and extratropical latitudes, respectively.

Tropopause temperature and upper tropospheric stability are by construction linked to each other. Nevertheless, a component of the variability in tropopause temperatures is linearly independent of variability in upper tropospheric stability. For example, Figure 12 shows the incidence of clouds averaged over 10-18 km in the tropical deep convective regime (left) and averaged over 6-12 km in the middle-/highlatitude regime (right) as a function of tropopause temperature (abscissa) and upper tropospheric stability (ordinate). The results in Figure 12 clearly indicate that cloud incidence varies as a function of tropopause temperature, even when the upper tropospheric static stability is held fixed, and vice versa.

2. Influence of thermodynamic and dynamic conditions near the surface. Sea surface temperature and lower tropospheric stability provide the thermodynamic and dynamic lower boundary conditions on tropospheric clouds. Both play a central role in determining the large-scale vertical structure of clouds throughout the global ocean on both long-term mean and month-to-month timescales.

In the subtropical regime, the long-term mean incidence of boundary layer clouds increases with decreasing SST and increasing lower tropospheric stability at rates of $3 \% \mathrm{~K}^{-1}$ and $10 \%$ per $\mathrm{K} \mathrm{km}^{-1}$, respectively. Similar linkages are observed on month-to-month timescales. For example, lower tropospheric stability 
Acknowledgments

We are indebted to Bjorn Stevens, Mark Zelinka, and Robert Wood for providing comments and suggestions. We would also like to thank Hui Su and two anonymous referees for their thorough reviews and insightful comments, which have led to considerable improvement in this work. Y.L. is funded by CloudSAT via NASA JPL and the NSF Climate Dynamics program. DWJT is funded by the NSF Climate Dynamics program. is positively correlated with cloud incidence between 0 and $3 \mathrm{~km}$ over the easternside of the subtropical ocean basins and along the eastern Pacific equatorial cold tongue (Figure 11a). Our results indicate that the opposite relationship holds between lower tropospheric stability and low-level clouds in the Arctic region, where the incidence of low-level clouds increases with decreasing lower tropospheric stability in both the long-term mean (Figure 8d) and on month-to-month timescales (Figure 11a).

3. The signature of midtropospheric vertical motion in cloud incidence. Large-scale vertical motion at $500 \mathrm{hPa}$ has a key signature in cloud incidence throughout the global ocean. Upper tropospheric cloud incidence increases with increasing ascent at a rate of $4 \%$ per $10 \mathrm{hPa} \mathrm{d}^{-1}$ in the deep tropics, $2 \%$ per $10 \mathrm{hPa} \mathrm{d}^{-1}$ over the Arctic, and $1 \%$ per $10 \mathrm{hPa} \mathrm{d}^{-1}$ at middle/high latitudes. Lower tropospheric cloud incidence increases with increasing descent at a rate of $1 \%$ per $10 \mathrm{hPa} \mathrm{d}^{-1}$ in the subtropical regime and at middle/high latitudes but increases with increasing ascent at a rate of $2 \%$ per $10 \mathrm{hPa} \mathrm{d}^{-1}$ over the Arctic. Upper tropospheric cloud incidence in the midlatitude storm track region is clearly linked to variance of large-scale vertical motion, which is indicative of the amplitude of baroclinic waves.

The results in this study provide a baseline for evaluating physical parameterizations of clouds in GCMs. They also serve as a reference for interpreting the signature of large-scale atmospheric phenomena in cloud vertical structure. In a companion study [Li et al., 2013], we examine the signature of the most prominent pattern of Northern Hemisphere climate variability in cloud vertical structure and radiative forcing.

\section{References}

Allan, R. P., A. Slingo, and M. A. Ringer (2002), Influence of dynamics on the changes in tropical cloud radiative forcing during the 1998 El Niño, J. Clim., 15, 1979-1986.

Barton, N. P., S. A. Klein, J. S. Boyle, and Y. Y. Zhang (2012), Arctic synoptic regimes: Comparing domain-wide arctic cloud observations with CAM4 and CAM5 during similar dynamics, J. Geophys. Res., 117, D15205, doi:10.1029/2012JD017589.

Behrangi, A., T. Kubar, and B. Lambrigtsen (2012), Phenomenological description of tropical clouds using CloudSat cloud classification, Mon. Weather Rev., 140, 3235-3249.

Blackmon, M. L., Y.-H. Lee, J. M. Wallace, and H.-H. Hsu (1984), Time variation of 500-mb height fluctuations with long, intermediate, and short time scales as deduced from lag-correlation statistics, J. Atmos. Sci., 41, 981-991.

Boehm, M. T., and S. Lee (2003), The implications of tropical Rossby waves for tropical tropopause cirrus formation and for the equatorial upwelling of the Brewer-Dobson circulation, J. Atmos. Sci., 60, 247-261.

Boehm, M. T., and J. Verlinde (2000), Stratospheric influence on upper tropospheric tropical cirrus, Geophys. Res. Lett., 27, 3209-3212, doi:10.1029/2000GL011678.

Bony, S., and J.-L. Dufresne (2005), Marine boundary layer clouds at the heart of tropical cloud feedback uncertainties in climate models, Geophys. Res. Lett., 33, L17810, doi:10.1029/2005GL023851.

Bony, S., K.-M. Lau, and Y. C. Sud (1997), Sea surface temperature and large-scale circulation influences on tropical greenhouse effect and cloud radiative forcing, J. Clim., 10, 2055-2077.

Bony, S., J.-L. Dufresne, H. LeTreut, J.-J. Morcrette, and C. Senior (2004), On dynamic and thermodynamic components of cloud changes, Clim. Dyn., 22, 71-86.

Bony, S., et al. (2006), How well do we understand and evaluate climate change feedback processes?, J. Clim., 19, 3445-3482, doi:10.1175/JCLI3819.1.

Brayshaw, D. J., B. Hoskins, and M. Blackburn (2008), The storm-track response to idealized SST perturbations in an aquaplanet GCM, J. Atmos. Sci., 65, 2842-2860.

Bretherton, C. S., M. Widmann, V. P. Dymnikov, J. M. Wallace, and I. Bladé (1999), The effective number of spatial degrees of freedom of a time-varying field, J. Clim., 12, 1990-2009.

Bromwich, D. H., et al. (2012), Tropospheric clouds in Antarctica, Rev. Geophys., 50, RG1004, doi:10.1029/2011RG000363.

Cess, R. D., M. Zhang, P.-H. Wang, and B. A. Wielicki (2001a), Cloud structure anomalies over the tropical Pacific during the 1997/98 El Niño, Geophys. Res. Lett., 28(24), 4547-4550, doi:10.1029/2001GL013750.

Cess, R. D., M. Zhang, B. A. Wielicki, D. F. Young, X. Zhou, and Y. Nikitenko (2001b), The influence of the 1998 El Niño upon cloud-radiative forcing over the Pacific warm pool, J. Clim., 14, 2129-2137.

Chen, T., Y. C. Zhang, and W. B. Rossow (2000), Sensitivity of atmospheric radiative heating rate profiles to variations of cloud layer overlap, J. Clim., 13, 2941-2959.

Chen, Y., and A. D. D. Genio (2009), Evaluation of tropical cloud regimes in observations and a general circulation mode, Clim. Dyn., 32, 355-369, doi:10.1007/S00382-008-0386-6.

Christensen, M. W., G. G. Carrió, G. L. Stephens, and W. R. Cotton (2013), Radiative impacts of free-tropospheric clouds on the properties of marine stratocumulus, J. Atmos. Sci., 70, 3102-3118, doi:10.1175/JAS-D-12-0287.1.

Clement, A. C. (2009), Observational and model evidence for positive low-level cloud feedback, Science, 325, 460-464, doi:10.1126/science.1171255.

Curry, J. A., W. B. Rossow, D. Randall, and J. L. Schramm (1996), Overview of arctic cloud and radiation characteristics, J. Clim., 9 , $1731-1764$.

Dee, D. P., et al. (2011), The ERA-Interim reanalysis: Configuration and performance of the data assimilation system, Q. J. R. Meteorol. Soc., 137, 553-597, doi:10.1002/qj.828.

Dima, I., and J. M. Wallace (2007), Structure of the annual-mean equatorial planetary waves in the ERA-40 reanalyses, J. Atmos. Sci., 64, 2862-2880, doi:10.1175/JAS3985.1.

Dufresne, J.-L., and S. Bony (2008), An assessment of the primary sources of spread of global warming estimates from coupled atmosphere-ocean models, J. Clim., 21, 5135-5144.

Eastman, R., and S. G. Warren (2010), Interannual variations of Arctic cloud types in relation to sea ice, J. Clim., 23, 4216-4232. 
Eastman, R., S. G. Warren, and C. J. Hahn (2011), Variations in cloud cover and cloud types over the ocean from surface observations, 1954-2008, J. Clim., 24, 5914-5934.

Eguchi, N., and M. Shiotani (2004), Intraseasonal variations of water vapor and cirrus clouds in the tropical upper troposphere, J. Geophys. Res., 109, D12106, doi:10.1029/2003JD004314.

Eitzen, Z. A., K.-M. Xu, and T. Wong (2011), An estimate of low-cloud feedbacks from variations of cloud radiative and physical properties with sea surface temperature on interannual time scale, J. Clim., 24, 1106-1121, doi:10.1175/2010JCLI3670.1.

Field, P. R., and R. Wood (2007), Precipitation and cloud structure in midlatitude cyclones, J. Clim., 20, 233-254.

Fu, R., A. D. D. Genio, and W. B. Rossow (1990), Behavior of deep convective clouds in the tropical Pacific deduced from ISCCP radiances, J. Clim., 3, 1129-1152, doi:10.1175/1520-0442.

George, R. C., and R. Wood (2010), Subseasonal variability of low cloud radiative properties over the southeast Pacific Ocean, Atmos. Chem. Phys., 10, 4047-4063, doi:10.5194/acp-10-4047-2010.

Gettelman, A., W. J. Randel, S. Massie, F. Wu, W. G. Read, and J. M. Russell III (2001), El Niño as a natural experiment for studying the tropical tropopause region, J. Clim., 14, 3375-3392.

Gettelman, A., W. J. Randel, F. Wu, and S. T. Massie (2002), Transport of water vapor in the tropical tropopause layer, Geophys. Res. Lett., 29(1), 1009, doi:10.1029/2001GL013818.

Gordon, N. D., J. R. Norris, C. P. Weaver, and S. A. Klein (2005), Cluster analysis of cloud regimes and characteristic dynamics of midlatitude synoptic systems in observations and a model, J. Geophys. Res., 110, D15S17, doi:10.1029/2004JD005027.

Grise, K. M., and D. W. J. Thompson (2012), Equatorial planetary waves and their signature in atmospheric variability, J. Atmos. Sci., 69, 857-874.

Guilyardi, E., P. Braconnot, F.-F. Jin, S. T. Kim, M. Kolasinski, T. Li, and I. Musat (2009), Atmosphere feedbacks during ENSO in a coupled GCM with a modified atmospheric convection scheme, J. Clim., 22, 5698-5718.

Hagihara, Y., H. Okamoto, and R. Yoshid (2010), Development of a combined CloudSat-CALIPSO cloud mask to show global cloud distribution, J. Geophys. Res., 115, D00H33, doi:10.1029/2009JD012344.

Hanson, H. P. (1991), Marine stratocumulus climatologies, Int. J. Climatol., 11, 147-164.

Im, E., S. L. Durden, and C. Wu (2005), Cloud profiling radar for the CloudSat mission, IEEE Trans. Aerosp. Electron. Syst., 20, 15-18.

Jensen, M. P., A. M. Vogelmann, W. D. Collins, G. J. Zhang, and E. P. Luke (2008), Investigation of regional and seasonal variations in marine boundary layer cloud properties from MODIS observations, J. Clim., 21, 4955-4873.

Jiang, J., et al. (2012), Evaluation of cloud and water vapor simulations in CMIP5 climate models using NASA "A-Train" satellite observations, J. Geophys. Res., 117, D14105, doi:10.1029/2011JD017237.

Jiang, X., D. E. Waliser, J.-L. Li, and C. Woods (2011), Vertical structures of cloud water associated with the boreal summer intraseasonal oscillation based on CloudSat observations and ERA-Interim reanalysis, Clim. Dyn., 36, 2219-2232, doi:10.1007/s00382-010-0853-8.

Kay, J. E., and A. Gettelman (2009), Cloud influence on and response to seasonal Arctic sea ice loss, J. Geophys. Res., 114, D18204, doi:10.1029/2009JD011773.

Kay, J. E., K. Raeder, A. Gettelman, and J. Anderson (2011), The boundary layer response to recent Arctic sea ice loss and implications for high-latitude climate feedbacks, J. Clim., 24, 428-447, doi:10.1175/2010JCLI3651.1.

Klein, S. A. (1997), Synoptic variability of low-cloud properties and meteorological parameters in the subtropical trade wind boundary layer, J. Clim., 10, 2018-2039.

Klein, S. A., and D. L. Hartmann (1993), The seasonal cycle of low stratiform clouds, J. Clim., 6, 1587-1606, doi:10.1175/1520-0442.

Klein, S. A., and C. Jakob (1999), Validation and sensitivities of frontal clouds simulated by the ECMWF model, Mon. Weather Rev., 127, 2514-2531.

Klein, S. A., D. L. Hartmann, and J. R. Norris (1995), On the relationships among low-cloud structure, sea surface temperature, and atmospheric circulation in the summertime northeast Pacific, J. Clim., 8, 1140-1155.

Klein, S. A., Y. Zhang, M. D. Zelinka, R. Pincus, J. Boyle, and P. J. Gleckler (2013), Are climate model simulations of clouds improving? An evaluation using the ISCCP simulator, J. Geophys. Res. Atmos., 118, 1329-1342, doi:10.1002/jgrd.50141.

Kubar, T., D. E. Waliser, J. Li, and X. Jiang (2012), On the annual cycle, variability, and correlations of oceanic low-topped clouds with large-scale circulation using Aqua MODIS and ECMWF-Interim, J. Clim., 25, 6152-6174, doi:10.1175/JCLI-D-11-00478.1.

Kubar, T. L., D. L. Hartmann, and R. Wood (2007), Radiative and convective driving of tropical high clouds, J. Clim., 20, 5510-5526, doi:10.1175/2007JCLI1628.1.

Kubar, T. L., D. E. Waliser, and J. Li (2011), Boundary layer and cloud structure controls on tropical low cloud cover using A-rain satellite data and ECMWF analyses, J. Clim., 24, 194-215, doi:10.1175/2010JCLI3702.1.

Kushnir, Y., W. A. Robinson, I. Bladé, N. M. J. Hall, S. Peng, and R. Sutton (2002), Atmospheric GCM response to extratropical SST anomalies: Synthesis and evaluation, J. Clim., 15, 2233-2256.

Lacagnina, C., and F. Selten (2013), Changes in the cloud properties in response to El Niño: A bivariate approach, Clim. Dyn., 40, 2973-2991, doi:10.1007/s00382-012-1645-0.

Lau, K.-M., H. T. Wu, and S. Bony (1997), The role of large-scale atmospheric circulation in the relationship between tropical convection and sea surface temperature, J. Clim., 10, 381-392.

Lau, N.-C., and M. W. Crane (1995), A satellite view of the synoptic-scale organization of cloud properties in midlatitude and tropical circulation systems, Mon. Weather Rev., 123, 1984-2006.

Lau, N.-C., and M. W. Crane (1997), Comparing satellite and surface observations of cloud patterns in synoptic-scale circulation systems, Mon. Weather Rev., 125, 3175-3189.

Li, J.-L. F., et al. (2012a), An observationally based evaluation of cloud ice water in CMIP3 and CMIP5 GCMs and contemporary reanalyses using contemporary satellite data, J. Geophys. Res., 117, D16105, doi:10.1029/2012JD017640.

$\mathrm{Li}$, Y., and D. W. J. Thompson (2013), The signature of the stratospheric Brewer-Dobson circulation in tropospheric clouds, J. Geophys. Res. Atmos., 118, 3486-3494, doi:10.1002/jgrd.50339.

Li, Y., P. Yang, G. R. North, and A. Dessler (2012b), Test of the fixed anvil temperature hypothesis, J. Atmos. Sci., 69, 2317-2328, doi:10.1175/JAS-D-11-0158.1.

Li, Y., D. W. J. Thompson, Y. Huang, and M. Zhang (2013), Observed linkages between the Northern Annular Mode/North Atlantic Oscillation, cloud incidence, and cloud radiative forcing, Geophys. Res. Lett., 41, 1-8, doi:10.1002/2013GL059113.

Lin, S.-J. (2004), A "vertically Lagrangian" finite-volume dynamical core for global models, Mon. Weather Rev., 132, 2293-2307.

Lin, W., M. Zhang, and N. Loeb (2009), Seasonal variation of the physical properties of marine boundary layer clouds off the California coast, J. Clim., 22, 2624-2638.

Lindzen, R. S., and B. Farrell (1980), A simple approximate result for the maximum growth rate of baroclinic instabilities, J. Atmos. Sci., 37, 1648-1654. 
Lindzen, R. S., and S. Nigam (1987), On the role of sea surface temperature gradients in forcing low level winds and convergence in the tropics, J. Atmos. Sci., 44, 2418-2436.

Mace, G. G., Q. Zhang, M. Vaughn, R. Marchand, G. Stephens, C. Trepte, and D. Winker (2009), A description of hydrometeor layer occurrence statistics derived from the first year of merged CloudSat and CALIPSO data, J. Geophys. Res., 114, D00A26, doi:10.1029/2007JD009755.

Marchand, R., G. G. Mace, T. Ackerman, and G. Stephens (2008), Hydrometeor detection using CloudSatAn Earth-orbiting 94-GHz cloud radar, J. Atmos. Oceanic Technol., 25, 519-533, doi:10.1175/2007JTECHA1006.1.

Masunaga, H., M. Satoh, and H. Miura (2008), A joint satellite and global cloud-resolving model analysis of a Madden-Julian Oscillation event: Model diagnosis, J. Geophys. Res., 113, D17210, doi:10.1029/2008JD009986.

Morrison, H., and J. O. Pinto (2005), Mesoscale modeling of springtime Arctic mixed-phase stratiform clouds using new two-moment bulk microphysics scheme, J. Atmos. Sci., 62, 3683-3704.

Nam, C., S. Bony, J.-L. Dufresne, and H. Chepfer (2012), The "too few, too bright" tropical low-cloud problem in CMIP5 models, Geophys. Res. Lett., 39, L21801, doi:10.1029/2012GL053421.

Naud, C., A. D. Genio, M. Bauer, and W. Kovari (2010), Cloud vertical distribution across warm and cold fronts in CloudSat-CALIPSO data and a general circulation model, J. Clim., 23, 3397-3415, doi:10.1175/2010JCLI3282.1.

Naud, C. M., A. D. Genio, and M. Baue (2006), Observational constraints on the cloud thermodynamic phase in midlatitude storms, J. Clim., 19, 5273-5288.

Norris, J. R. (1998), Low cloud type over the ocean from surface observations. Part II: Geographical and seasonal variations, J. Clim., 11, 383-403.

Norris, J. R. (2000), Interannual and interdecadal variability in the storm track, cloudiness, and sea surface temperature over the summertime North Pacific, J. Clim., 13, 422-430.

Norris, J. R., and S. F. lacobellis (2005), North Pacific cloud feedbacks inferred from synoptic-scale dynamic and thermodynamic relationships, J. Clim., 18, 4862-4878.

Norris, J. R., and S. A. Klein (2000), Low cloud type over the ocean from surface observations. Part III: Relationship to vertical motion and the regional surface synoptic environment, J. Clim., 13, 245-256.

Norris, J. R., and C. B. Leovy (1994), Interannual variability in stratiform cloudiness and sea surface temperature, J. Clim., 7, 1915-1925.

Norris, J. R., and C. P. Weaver (2001), Improved techniques for evaluating GCM cloudiness applied to the NCAR CCM3, J. Clim., 14, 2540-2550.

Norton, W. A. (2006), Tropical wave driving of the annual cycle in tropical tropopause temperatures. Part II: Model results, J. Atmos. Sci., 63, 1420-1431, doi:10.1175/JAS3698.1.

Oreopoulos, L., and R. Davies (1993), Statistical dependence of the albedo and cloud cover of tropical marine stratocumulus on sea surface temperature, J. Clim., 6, 2434-2447.

Palm, S. P., S. T. Strey, J. Spinhirne, and T. Markus (2010), Influence of Arctic sea ice extent on polar cloud fraction and vertical structure and implications for regional climate, J. Geophys. Res., 115, D21209, doi:10.1029/2010JD013900.

Park, S., and C. B. Leovy (2004), Marine low-cloud anomalies associated with ENSO, J. Clim., 17, 3448-3469.

Pinto, J. O. (1998), Autumnal mixed-phase cloudy boundary layers in the Arctic, J. Atmos. Sci., 55, 2016-2038.

Posselt, D. J., G. L. Stephens, and M. Miller (2008), CLOUDSAT: Adding a new dimension to a classical view of extratropical cyclones, Bull. Am. Meteorol. Soc., 89, 599-609.

Ramanathan, V., and W. Collins (1991), Thermodynamics regulation of ocean warming by cirrus clouds deduced from observations of the 1987 El Niño, Nature, 351, 27-32.

Ramanathan, V., R. D. Cess, E. F. Harrison, P. Minnis, B. R. Barkstrom, E. Ahmad, and D. Hartmann (1989), Cloud-radiative forcing and climate: Results from the Earth radiation budget experiment, Science, 243, 57-63.

Randall, D. A., Harshvardhan, D. A. Dazlich, and T. G. Corsett (1989), Interactions among radiation, convection, and large-scale dynamics in a general circulation model, J. Atmos. Sci., 46, 1943-1970.

Randall, D. A., et al. (2007), Climate models and their evaluation, in Climate Change 2007: The Physical Science Basis. Contribution of Working Group I to the Fourth Assessment Report of the Intergovernmental Panel on Climate Change, edited by S. Solomon et al., pp. 589-662, Cambridge Univ. Press, Cambridge, U. K., and New York.

Richter, I., and C. R. Mechoso (2004), Orographic influences on the annual cycle of Namibian stratocumulus clouds, Geophys. Res. Lett., 31, L24108, doi:10.1029/2004GL020814.

Richter, I., and C. R. Mechoso (2006), Orographic influences on subtropical stratocumulus, J. Atmos. Sci., 63, 2585-2601.

Riley, E. M., B. E. Mapes, and S. N. Tulich (2011), Clouds associated with the Madden-Julian oscillation: A new perspective from CloudSat, J. Atmos. Sci., 68, 3032-3051, doi:10.1175/JAS-D-11-030.1.

Rossow, W. B., and A. A. Lacis (1990), Global, seasonal cloud variations from satellite radiance measurements. Part II. Cloud properties and radiative effects, J. Clim., 3, 1204-1253.

Rossow, W. B., and R. A. Schiffer (1991), ISCCP cloud data products, Bull. Am. Meteorol. Soc., 72, 2-20.

Rossow, W. B., and R. A. Schiffer (1999), Advances in understanding clouds from ISCCP, Bull. Am. Meteorol. Soc., 80, 2261-2287.

Sassi, F., M. Salby, and W. G. Read (2001), Relationship between upper tropospheric humidity and deep convection, J. Geophys. Res., 106, $17,133-17,146$.

Sato, K., J. Inoue, Y.-M. Kodama, and J. E. Overland (2012), Impact of Arctic sea-ice retreat on the recent change in cloud-base height during autumn, Geophys. Res. Lett., 39, L10503, doi:10.1029/2012GL051850.

Simmons, A., S. Uppala, D. Dee, and S. Kobayashi (2007), ERA-Interim: New ECMWF Reanalysis Products From 1989 Onwards, ECMWF Newsletter, 110, 25-35, ECMWF, Reading, U. K.

Slingo, A., and J. M. Slingo (1988), The response of a general circulation model to cloud longwave radiative forcing. I: Introduction and initial experiments, Q. J. R. Meteorol. Soc., 114, 1027-1062.

Soden, B. J., and R. Fu (1995), A satellite analysis of deep convection, upper-tropospheric humidity, and the greenhouse effect, J. Clim., 8, 2335-2351.

Soden, B. J., and I. M. Held (2006), An assessment of climate feedbacks in coupled ocean-atmosphere models, J. Clim., 19, 3354-3360.

Stephens, G., et al. (2002), The CloudSat mission and the A-train: A new dimension of space-based observations of clouds and precipitation, Bull. Am. Meteorol. Soc., 83, 1771-1790, doi:10.1175/BAMS-83-12-1771.

Stephens, G. L. (2005), Cloud feedbacks in the climate system: A critical review, J. Clim., 18, 237-273.

Stevens, B. (2007), On the growth of layers of non-precipitating cumulus convection, J. Atmos. Sci, 64, 2916-2931.

Su, H., and J. H. Jiang (2013), Tropical clouds and circulation changes during the 2006-07 and 2009-10 El Niños, J. Clim., 26, 399-413, doi:10.1175/JCLI-D-12-00152.1. 
Su, H., W. G. Read, J. H. Jiang, J. W. Waters, D. L. Wu, and E. J. Fetzer (2006a), Enhanced positive water vapor feedback associated with tropical deep convection: New evidence from Aura MLS, Geophys. Res. Lett., 33, L05709, doi:10.1029/2005GL025505.

Su, H., D. E. Waliser, J. H. Jiang, J. Li, W. G. Read, J. W. Waters, and A. M. Tompkins (2006b), Relationships of upper tropospheric water vapor, clouds and SST: MLS observations, ECMWF analyses and GCM simulations, Geophys. Res. Lett., 33, L22802, doi:10.1029/2006GL027582.

Su, H., J. H. Jiang, D. G. Vane, and G. L. Stephens (2008), Observed vertical structure of tropical oceanic clouds sorted in large-scale regime, Geophys. Res. Lett., 35, L24704, doi:10.1029/2008GL035888.

Su, H., J. H. Jiang, J. Teixeira, A. Gettelman, X. Huang, G. Stephens, D. Vane, and V. S. Perun (2011), Comparison of regime-sorted tropical cloud profiles observed by CloudSat with GEOS 5 analyses and two general circulation model simulations, J. Geophys. Res., 116, D09104, doi:10.1029/2010JD014971.

$\mathrm{Su}, \mathrm{H}$., et al. (2013), Diagnosis of regime-dependent cloud simulation errors in CMIP5 models using A-Train satellite observations and reanalysis data, J. Geophys. Res. Atmos., 118, 2762-2780, doi:10.1029/2012JD018575.

Trenberth, K. E. (1991), Storm tracks in the Southern Hemisphere, J. Atmos. Sci., 48, 2159-2178.

Tromeur, E., and W. B. Rossow (2010), Interaction of tropical deep convection with the large-scale circulation in the MJO, J. Clim., 23, 1837-1853, doi:10.1175/2009JCLI3240.1.

Tselioudis, G., and C. Jakob (2002), Evaluation of midlatitude cloud properties in a weather and a climate model: Dependence on dynamic regime and spatial resolution, J. Geophys. Res., 107(D24), 4781, doi:10.1029/2002JD002259.

Tselioudis, G., Y. Zhang, and W. B. Rossow (2000), Cloud and radiation variations associated with northern midlatitude low and high sea level pressure regimes, J. Clim., 13, 312-327.

Vaughan, M., et al. (2010), Strategies for improved CALIPSO aerosol optical depth estimates, paper presented at 25th International Laser Radar Conference (ILRC), St. Petersburg, Russia. [Available at http://www-calipso.larc.nasa.gov/resources/pdfs/ILRC_LaRC_2010/ Vaughan_ILRC25_2010.pdf; http://www-calipso.larc.nasa.gov/resources/pdfs/ILRC_LaRC_2010/Vaughan_ILRC25_2010.pdf.]

Verlinden, K. L., D. W. J. Thompson, and G. L. Stephens (2011), The three-dimensional distribution of clouds over the Southern Hemisphere high latitudes, J. Clim., 24, 5799-5811.

Virts, K. S., and J. M. Wallace (2010), Annual, interannual, and intraseasonal variability of tropical tropopause transition layer cirrus, J. Atmos. Sci., 67, 3097-3112.

Waliser, D. E., N. E. Graham, and C. Gautier (1993), Comparison of the highly reflective cloud and outgoing longwave radiation data sets for use in estimating tropical deep convection, J. Clim., 6, 331-353.

Wallace, J. M., G. Lim, and M. L. Blackmon (1988), Relationship between cyclone tracks, anticyclone tracks, and baroclinic waveguides, J. Atmos. Sci., 45, 439-462.

Weare, B. C. (2000), Insights into the importance of cloud vertical structure in climate, Clim. Dyn., 27, 907-910.

Weaver, C. P., and V. Ramanathan (1996), The link between summertime cloud radiative forcing and extratropical cyclones in the North Pacific, J. Clim., 9, 2093-2109.

Weaver, C. P., and V. Ramanathan (1997), Relationships between large-scale vertical velocity, static stability, and cloud radiative forcing over Northern Hemisphere extratropical oceans, J. Clim., 10, 2871-2887.

Webb, M., C. Senior, S. Bony, and J. J. Morcrette (2001), Combining ERBE and ISCCP data to assess clouds in the Hadley Centre, ECMWF and LMD atmospheric climate models, Clim. Dyn., 17, 905-922.

Wielicki, B. A., and L. Parker (1992), On the determination of cloud cover from satellite sensors: The effect of sensor spatial resolution, J. Geophys. Res., 97, 12,799-12,823.

Wielicki, B. A., E. F. Harrison, R. D. Cess, M. D. King, and D. A. Randall (1995), Mission to planet Earth: Role of clouds and radiation in climate, Bull. Am. Meteorol. Soc., 76, 2125-2153.

Winker, D. M., W. H. Hunt, and M. J. McGill (2007), Initial performance assessment of CALIOP, Geophys. Res. Lett., 34, L19803, doi:10.1029/2007GL030135.

Winker, D. M., M. A. Vaughan, A. Omar, Y. Hu, K. A. Powell, Z. Liu, W. H. Hunt, and S. A. Young (2009), Overview of the CALIPSO mission and CALIOP data processing algorithms, J. Atmos. Oceanic Technol., 26, 2310-2323, doi:10.1175/2009JTECHA1281.1.

Winker, D. M., et al. (2010), The CALIPSO mission: A global 3D view of aerosols and clouds, Bull. Am. Meteorol. Soc., 91, 1211-1229, doi:10.1175/2010BAMS3009.1.

Wood, R. (2012), Stratocumulus clouds, Mon. Weather Rev., 140, 2373-2423, doi:10.1175/MWR-D-11-00121.1.

Wood, R., and C. S. Bretherton (2006), On the relationship between stratiform low cloud cover and lower-tropospheric stability, J. Clim., 19, 6425-6432, doi:10.1175/JCLI3988.1.

Wu, D. L., and J. N. Lee (2012), Arctic low cloud changes as observed by MISR and CALIOP: Implication for the enhanced autumnal warming and sea ice loss, J. Geophys. Res., 117, D07107, doi:10.1029/2011JD017050.

Wyant, M. C., C. S. Bretherton, H. A. Rand, and D. E. Stevens (1997), Numerical simulations and a conceptual model of the stratocumulus to trade cumulus transition, J. Atmos. Sci., 54, 169-192.

Wyant, M. C., C. S. Bretherton, J. T. Bacmeister, J. T. Kiehl, I. M. Held, M. Zhao, S. A. Klein, and B. J. Soden (2006), A comparison of low-latitude cloud properties and their response to climate change in three AGCMs sorted into regimes using mid-tropospheric vertical velocity, Clim. Dyn., 27, 261-279, doi:10.1007/s00382-006-0138-4.

Yuan, J., and R. A. Houze (2013), Deep convective systems observed by A-Train in the tropical Indo-Pacific region affected by the MJO, J. Atmos. Sci., 70, 456-486, doi:10.1175/JAS-D-12-057.1.

Yuan, T., and L. Oreopoulos (2013), On the global character of overlap between low and high clouds, Geophys. Res. Lett., 40, 5320-5326, doi:10.1002/grl.50871.

Zelinka, M. D., and D. L. Hartmann (2011), The observed sensitivity of high clouds to mean surface temperature anomalies in the tropics, J. Geophys. Res., 116, D23103, doi:10.1029/2011JD016459.

Zhang, C. (1993a), On the annual cycle in highest, coldest clouds in the tropics, J. Clim., 6, 1987-1990.

Zhang, C. (1993b), Large-scale variability of atmospheric deep convection in relation to sea surface temperature in the tropics, J. Clim., 6 , 1898-1913.

Zhang, M. H., R. D. Cess, and S. C. Xie (1996), Relationship between cloud radiative forcing and sea surface temperatures over the entire tropical oceans, J. Clim., 9, 1374-1384.

Zhang, M. H., et al. (2005), Comparing clouds and their seasonal variations in 10 atmospheric general circulation models with satellite measurement, J. Geophys. Res., 110, D15S02, doi:10.1029/2004JD005021.

Zhang, Y., S. Klein, G. G. Mace, and J. Boyl (2007), Cluster analysis of tropical clouds using CloudSat data, Geophys. Res. Lett., 34, L12813, doi:10.1029/2007GL029336. 
Zhao, M., and Z. Wang (2010), Comparison of Arctic clouds between European Center for Medium-Range Weather Forecasts simulations and Atmospheric Radiation Measurement Climate Research Facility long-term observations at the North Slope of Alaska Barrow site, J. Geophys. Res., 115, D23202, doi:10.1029/2010JD014285.

Zhu, P., J. J. Hack, J. T. Kiehl, and C. S. Bretherton (2007), Climate sensitivity of tropical and subtropical marine low cloud amount to ENSO and global warming due to doubled CO2, J. Geophys. Res., 112, D17108, doi:10.1029/2006JD008174.

Zuidema, P., B. Baker, and Y. Han (2004), An arctic springtime mixed phase cloudy boundary layer observed during SHEBA, J. Atmos. Sci., $62,160-178$. 